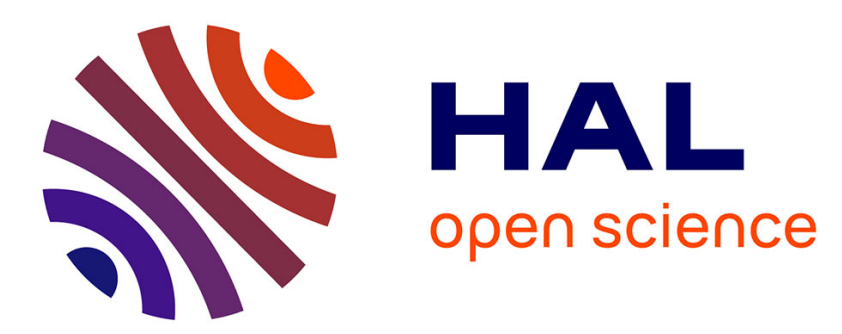

\title{
Thermal aging of High Tenacity Polyvinyl Alcohol yarns
} Yan Bian, Xavier Colin, Matthieu Aressy

\section{To cite this version:}

Yan Bian, Xavier Colin, Matthieu Aressy. Thermal aging of High Tenacity Polyvinyl Alcohol yarns. Polymer Degradation and Stability, 2020, 179, pp.109277. 10.1016/j.polymdegradstab.2020.109277. hal-02931763

\section{HAL Id: hal-02931763 https://hal.science/hal-02931763}

Submitted on 7 Sep 2020

HAL is a multi-disciplinary open access archive for the deposit and dissemination of scientific research documents, whether they are published or not. The documents may come from teaching and research institutions in France or abroad, or from public or private research centers.
L'archive ouverte pluridisciplinaire HAL, est destinée au dépôt et à la diffusion de documents scientifiques de niveau recherche, publiés ou non, émanant des établissements d'enseignement et de recherche français ou étrangers, des laboratoires publics ou privés. 


\title{
Thermal aging of High Tenacity Polyvinyl Alcohol yarns
}

\author{
Yan Bian ${ }^{\mathrm{a}, \mathrm{b}}$, Xavier Colin ${ }^{\mathrm{a},{ }^{*} \text {, Matthieu Aressy }}{ }^{\mathrm{b}}$ \\ a PIMM, Arts et Métiers Institute of Technology, CNRS, CNAM, HESAM University, 151 Boulevard de l'Hôpital, 75013 Paris, France \\ ${ }^{\mathrm{b}}$ TERRE ARMEE Internationale, 280 Avenue Napoleon Bonaparte, 92500 Rueil Malmaison, France
}

Keywords:

Poly(vinyl alcohol)

Yarns

Geosynthetics

Thermal aging

Oxidation

Dehydration

Crystalline morphology

Fracture properties

\begin{abstract}
A B S T R A C T
A both multiscale and multi-techniques approach was developed to characterize the thermal aging in air at 70, 90, 100 and $120{ }^{\circ} \mathrm{C}$ of High Tenacity Polyvinyl Alcohol (HT-PVAl) yarns, and to elucidate the consequences of thermal aging on the chemical structure, crystalline morphology and several physicochemical and mechanical properties of practical interest. First of all, FTIR and UV-Vis spectrometries showed that the main degradation products are isolated $\left(1656 \mathrm{~cm}^{-1}\right)$ and conjugated $\left(1592 \mathrm{~cm}^{-1}\right)$ carbon-carbon double bonds, and a large variety of carbonyl products such as: esters $\left(1757 \mathrm{~cm}^{-1}\right), \mathrm{al}^{-}$ dehydes $\left(1737 \mathrm{~cm}^{-1}\right)$, carboxylic acids $\left(1720 \mathrm{~cm}^{-1}\right)$, ketones $\left(1707 \mathrm{~cm}^{-1}\right)$, but also polyenones (1630 $\mathrm{cm}^{-1}$ ). Possible mechanistic schemes were then proposed to explain the formation of all these different degradation products. Moreover, no change in the physico-chemical properties of the amorphous phase was detected by modulated differential scanning calorimetry and dynamic vapor sorption. In contrast, the decrease in both melting temperature and crystallinity ratio with exposure time clearly indicates a "nibbling" of the crystalline phase during thermal aging, thus highlighting a chemical attack preferentially localized at the amorphous/crystal interface for this complex anisotropic material. This heterogeneous degradation is responsible for the loss of fracture properties in tension of HT-PVAl yarns. Fairly simple relationships between the structural variables determined at the different scales of analysis were established. As an example, a linear correlation was found between the changes in fracture properties and the changes in crystalline morphology.
\end{abstract}

\section{Introduction}

For more than a decade now, High Tenacity Polyvinyl Alcohol (HT-PVAl) yarns have been attracting a lot of interest in the geosynthetic community, particularly for their reinforcement function [1-4]. PVAl interest principally lies in its excellent resistance to strongly alkaline or acidic environments combined with a high stiffness and good creep performances [4-6] that makes it a serious alternative material to Polypropylene (PP), Polyamides (PA) and Poly(Ethylene Terephthalate) (PET) for reinforcement applications particularly in chemically aggressive soils. Today, several products manufactured with HT-PVAl yarns are marketed in various forms such as: geotextiles, geogrids, geobands, fiber reinforced concretes or asphalts, tires, pipes, cooling systems (durits) and conveyor belts. In civil engineering, the demand of HT-PVAl yarns is boosted by the increasing use of soil treatments, recycled materials or low quality fills with extreme $\mathrm{pH}$ conditions [7, 8]. Despite this growing

\footnotetext{
* Corresponding author.

E-mail address: xavier.colin@ensam.eu (X. Colin).
}

attraction for PVAl, the characterization of the yarn microstructure and its physico-chemical and mechanical properties remains an open issue for the scientific community even today, as well as a challenge for standardization organizations who face difficulties in specifying this material and assessing its long-term durability.

This paper is dedicated to the thermal aging of HT-PVAl yarns in air between 70 and $120^{\circ} \mathrm{C}$. A both multiscale and multi-techniques approach was developed to characterize and elucidate the consequences of the thermal ageing at different scales of analysis. At the molecular scale, the changes in the chemical structure of HT-PVAl yarns were revealed by UV-Visible and Fourier transform infrared (FTIR) spectrometries. These two complementary techniques were used to identify and quantify the main oxidation products. At the macromolecular and morphological scales, the changes in the macromolecular and crystalline structures of HTPVAl yarns were determined by modulated differential scanning calorimetry (MDSC). Particular attention was paid to the changes in the glass transition temperature $\left(\mathrm{T}_{\mathrm{g}}\right)$, melting temperature $\left(\mathrm{T}_{\mathrm{m}}\right)$ and crystallinity ratio $\left(\mathrm{X}_{\mathrm{c}}\right)$. At the macroscopic scale, on the one hand, the possible consequences of thermal aging on the water content of 
HT-PVAl yarns were investigated by MDSC and dynamic water sorption (DVS). On the other hand, the consequences on the mechanical properties of HT-PVAl yarns were determined by uniaxial tensile testing.

\section{Material and methods}

\subsection{Material}

HT-PVAl yarns referenced K5501 with a linear density of 2000 dTex were supplied by Kuraray. Each yarn consists in approximately a thousand of elementary filaments of about $20 \mu \mathrm{m}$ diameter.

As HT-PVAl yarns can absorb significant amounts of water (e.g. $5.5 \mathrm{wt} \%$ at $22{ }^{\circ} \mathrm{C}$ in $100 \% \mathrm{RH}$ ), their physico-chemical and mechanical properties are very sensitive to small variations in relative humidity. In order to eliminate this important source of experimental scattering, before any aging and characterization experiment, all the samples were stored for at least two weeks in an airconditioned room, in particular at a nominal temperature of $22{ }^{\circ} \mathrm{C}$ and a relative humidity of $50 \%$. Indeed, it was checked that all the samples had reached their equilibrium moisture content (typically $1.8 \mathrm{wt} \%)$ following this specific environmental exposure.

In order to guarantee the quantity of samples required for all physico-chemical and mechanical analyses, at least $4 \mathrm{~m}$ of yarns were tightly wound up and blocked at their ends onto borosilicate glass test tubes. These assemblies were then submitted to thermal aging.

\subsection{Exposure conditions}

Thermal aging was performed at $70,90,100$ and $120^{\circ} \mathrm{C}$ in airventilated ovens regulated at $\pm 1{ }^{\circ} \mathrm{C}$. Each sample assembly (i.e. test tube with coiled HT-PVAl yarn) was periodically removed from the oven, cooled to room temperature and stored for at least two weeks in an air-conditioned room (i.e. at $22{ }^{\circ} \mathrm{C}$ in $50 \% \mathrm{RH}$ ) before any characterization.

\subsection{Protocol for film preparation}

In order to perform quantitative spectrometric analyzes using the classical Beer-Lambert's law, thin films of PVAl were produced after the complete dissolution of HT-PVAl yarns in dimethyl sulfoxide (DMSO), known to be a good solvent for PVAl [5].

wFor FTIR analyses, $50 \mathrm{mg}$ of HT-PVAl yarns were cut into small pieces and introduced in a glass beaker with $4 \mathrm{ml}$ of DMSO. The mixture was stirred at $120^{\circ} \mathrm{C}$ for $16 \mathrm{~h}$ until reaching a transparent homogeneous solution. After cooling to room temperature, a small volume of this solution ( 30 drops) was casted in a Petri dish. Then, the remaining solvent was slowly evaporated at $80^{\circ} \mathrm{C}$ under primary vacuum for $24 \mathrm{~h}$. This protocol leads to the formation of homogeneous and regular films of PVAl with an average thickness of $10 \pm 2 \mu \mathrm{m}$.

For UV-Visible analyses, the same protocol was adopted but the initial mass of HT-PVAl yarns was increased up to $100 \mathrm{mg}$ in order to obtain thicker PVAl films with an average thickness of $25 \pm 2 \mu \mathrm{m}$.

\subsection{Physico-chemical characterization}

\subsubsection{Fourier-transform infrared spectrometry}

FTIR analyzes were performed in transmission mode on PVAl films to follow the changes in chemical composition during thermal aging. FTIR spectra were obtained with a PerkinElmer Frontier FTIR spectrophotometer between 400 and $4000 \mathrm{~cm}^{-1}$ after having averaged the 16 scans obtained with a minimum resolution of 4 $\mathrm{cm}^{-1}$. All spectra were recorded in absorbance mode and analyzed with the Spectrum software.
The concentration $\mathrm{C}$ of the different functional groups of practical interest (i.e. consumed or formed during thermal aging) was determined from the absorbance A of their characteristic IR absorption band applying the classical Beer-Lambert's law:

$C=\frac{A}{e \times \varepsilon}$

where e is the film thickness (expressed in $\mathrm{cm}$ ) and $\varepsilon$ the molar extinction coefficient (in L. mol ${ }^{-1} \cdot \mathrm{cm}^{-1}$ ).

FTIR spectrometry was coupled with the chemical derivation method, which consists in exposing aged PVAl samples to ammonia gas $\left(\mathrm{NH}_{3}\right)$, in order to identify and quantify more easily and unambiguously the different carbonyl species formed during the thermal aging [9]. This chemical treatment acts on [10, 11]:

- Carboxylic acids by transforming them into ammonium carboxylates, which shifts their IR absorption band from 1700 to $1740 \mathrm{~cm}^{-1}$ to $1550^{-1} 600 \mathrm{~cm}^{-1}$ :

$\mathrm{RCOOH}+\mathrm{NH}_{3} \rightarrow \mathrm{RCO}_{2}^{-}, \mathrm{NH}_{4}^{+}$

- Esters and lactones by transforming them into primary amides, which shifts their IR absorption band from 1730 to $1850 \mathrm{~cm}^{-1}$ to $1620-1680 \mathrm{~cm}^{-1}$ :

$\mathrm{RCOOR}^{\prime}+\mathrm{NH}_{3} \rightarrow \mathrm{RCONH}_{2}+\mathrm{R}^{\prime} \mathrm{OH}$

To carry out this chemical derivation, PVAl films were placed on a perforated ceramic plate over an aqueous ammonia solution (in excess) in a sealed desiccator for one week, leaving the $\mathrm{NH}_{3}$ vapors react completely with carboxylic acids and esters. After this $\mathrm{NH}_{3}$ treatment, the films were dried under vacuum at $80^{\circ} \mathrm{C}$ for $24 \mathrm{~h}$ and then analyzed by FTIR spectrometry. The difference between the FTIR spectra obtained before and after $\mathrm{NH}_{3}$ treatment allowed the identification and titration of the different carbonyl species formed during the thermal aging of HT-PVAl yarns.

\subsubsection{Ultraviolet-visible spectrometry}

UV-Visible analyzes were performed in transmission mode on PVAl films to detect the eventual formation of unsaturated structures (polyenes and polyenones) during thermal aging. UV-Vis spectra were obtained with a PerkinElmer Lambda $35 \mathrm{UV}-\mathrm{Vis}$ spectrophotometer between 200 and $400 \mathrm{~nm}$ and were analyzed with the Spectrum software.

\subsubsection{Modulated differential scanning calorimetry (MDSC)}

Differential Scanning Calorimetric analyses were performed with modulated temperature (MDSC) on HT-PVAl yarns to follow the changes in the transition temperatures between physical states ( $\mathrm{T}_{\mathrm{g}}$ and $\mathrm{T}_{\mathrm{m}}$ ), crystallinity ratio $\left(\mathrm{X}_{\mathrm{c}}\right)$ and water content during thermal aging. Analyses were carried out with a TA instruments DSCQ1000 calorimeter under nitrogen from -60 to $350{ }^{\circ} \mathrm{C}$ with a constant heating rate of $3{ }^{\circ} \mathrm{C} \cdot \mathrm{min}^{-1}$. The applied modulated temperature was $\pm 2{ }^{\circ} \mathrm{C} / 60$ s.

The melting temperature $\left(\mathrm{T}_{\mathrm{m}}\right)$ and enthalpy $\left(\Delta \mathrm{H}_{\mathrm{m}}\right)$ were determined from the global heat flow curve. $T_{m}$ was taken at the maximum of the melting peak of PVAl, whereas $\Delta \mathrm{H}_{\mathrm{m}}$ was determined as the area under the melting peak. The crystallinity ratio $\mathrm{X}_{\mathrm{c}}$ was then deduced as follows: 
$\mathrm{X}_{\mathrm{c}}(\%)=\frac{\Delta \mathrm{H}_{\mathrm{m}}}{\Delta \mathrm{H}_{\mathrm{m}}^{0}} \times 100$

where $\Delta H_{m}^{0}=161{\mathrm{~J} . g^{-1}}^{-1}[12,13]$, is the melting enthalpy of the PVAl crystal.

Regarding the glass transition temperature $\left(\mathrm{T}_{\mathrm{g}}\right)$ and water content, it was previously reported that the glass transition and water evaporation are overlapped on the global heat flow curve for the HT-PVAl yarn [4]. That is the reason why MDSC was used to separate both phenomena on the reversing and non-reversing heat flow curves, respectively. $T_{g}$ was taken at the inflection point on the reversing heat flow curve, whereas the enthalpy of water evaporation $\left(\Delta \mathrm{H}_{\mathrm{vap}, \mathrm{H} 2 \mathrm{O}}\right)$ was determined as the area under the endothermic peak on the non-reversing curve. The water content was then deduced as follows:

water content $(\%)=\frac{\Delta \mathrm{H}_{\mathrm{vap}, \mathrm{H}_{2} \mathrm{O}}}{\Delta \mathrm{H}_{\text {latent }, \mathrm{H}_{2} \mathrm{O}}} \times 100$

where $\Delta H_{\text {latent,H2O }}=2265 \mathrm{~J} \cdot g^{-1}$, is the latent heat of water vaporization.

\subsubsection{Dynamic vapor sorption (DVS)}

Sorption experiments were carried out on HT-PVAl yarns to monitor the eventual changes in water content due to the formation of additional polar structures (hydroxyls and carbonyls) during thermal aging. All measurements were performed on dried HTPVAl yarns of few $\mathrm{mm}$ long at $60^{\circ} \mathrm{C}$.

Measurements in wet atmosphere (typically between 0 and $90 \%$ RH) were realized with a Surface Measurement System DVS-1000 analyzer. Very briefly, this analyzer is composed of a climatic chamber equipped with an ultra-sensitive Cahn's microbalance with electromagnetic compensation allowing to access mass changes up to $\pm 0.1 \mu \mathrm{g}$ as a function of temperature and relative humidity. The moisture content in the chamber is set between 0 and $90 \% \mathrm{RH}$ by mixing wet ( $100 \% \mathrm{RH})$ and dry (0\% RH) nitrogen streams. In addition, the temperature is precisely controlled using a continuous fluid circulation via a loop inside the chamber.

HT-PVAl yarn samples were placed in a glass dish suspended from the microbalance by a wire. Before any sorption experiment, the samples were dried at $60^{\circ} \mathrm{C}$ in a $0 \% \mathrm{RH}$ atmosphere (at least $4 \mathrm{~h}$ ) in order to remove any traces of water adsorbed on their surface until the establishment of a horizontal baseline, corresponding to the mass of the fully dry material. Once completed this preliminary drying stage, the moisture was introduced at the desired relative humidity in the already heated climatic chamber. The changes in the sample mass were directly monitored in a computer and recorded throughout the test ( $12 \mathrm{~h}$ recording for each humidity).

Measurements in a fully saturated wet atmosphere (i.e. denoted as $100 \% \mathrm{RH}$ ) were realized by immersion in pure distilled water. HTPVAl yarn samples were removed periodically from the bath to be manually weighted on a common laboratory microbalance. Before weighting, the yarns were wiped with Joseph paper to remove any traces of water flowing on their surface.

It was found that the resulting sorption curves obey the classical Fick's second law. Indeed, in these curves, two time domains can be clearly distinguished: a transient domain during which the water content increases linearly with the square root of time, then a final saturation plateau for which the water content has reached its equilibrium value $\left(\mathrm{W}_{\mathrm{S}}\right)$ throughout the yarn diameter. Only this equilibrium value was considered in this study. $\mathrm{W}_{\mathrm{S}}$ was plotted versus relative humidity to discuss the shape of the so-called sorption isotherms.

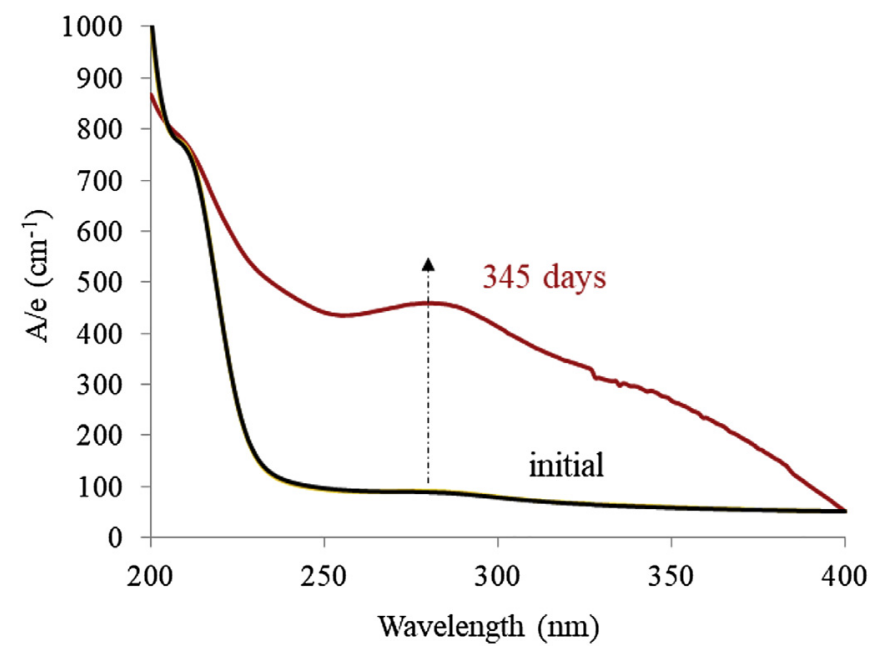

Fig. 1. UV-Vis spectra (normalized by the film thickness) of PVAl films before (a) and after 345 days of thermal exposure in air at $100{ }^{\circ} \mathrm{C}(\mathrm{b})$.

\subsection{Mechanical characterization: Uniaxial tensile tests}

Uniaxial tensile tests were carried out on HT-PVAl yarns according to the ASTM D2256 standard to monitor the consequences of thermal aging on fracture properties. Experiments were performed on HT-PVAl yarn samples of $250 \mathrm{~mm}$ long with a Tinius Olsen Pneumatic Grip Controller HT400 tensile machine equipped with a $500 \mathrm{~N}$ force cell and pneumatic jaws specially adapted for yarn characterization. Each test was conducted at room temperature $\left(25^{\circ} \mathrm{C}\right)$ with a preload of $0.5 \mathrm{~N}$ and a constant crosshead speed of $250 \mathrm{~mm} \cdot \mathrm{min}^{-1}$, and repeated five times to consider the experimental scattering and to give a representative average value for the fracture properties under consideration, i.e. strength and strain at rupture.

\section{Results \& discussion}

\subsection{Changes at the molecular scale}

\subsubsection{UV-Vis spectrometry}

As an example, Fig. 1 (a) shows the UV-Vis spectra (normalized by the film thickness) of PVAl films before and after 345 days of thermal exposure in air at $100{ }^{\circ} \mathrm{C}$. Recall that these PVAl films were produced from HT-PVAl yarns according to the protocol described in Section 2.3. It can be seen that thermal ageing leads to an increase of the UV-Vis absorption between 210 and $400 \mathrm{~nm}$, the largest increase being located between 220 and $300 \mathrm{~nm}$.

For a better viewing of the effects of thermal aging, the spectrum of the unaged PVAl film was then regularly subtracted from all the spectra of the aged PVAl films. Fig. 2 shows the changes (normalized by the film thickness) in the UV-Vis spectrum of PVAl films during the first hundred days of thermal exposure in air at 70, 90,100 and $120^{\circ} \mathrm{C}$, respectively.

It can be observed that, at $70{ }^{\circ} \mathrm{C}$, almost no sign of aging is detected over the entire wavelength range under consideration, even after 511 days of exposure. In contrast, at 90,100 and $120^{\circ} \mathrm{C}$, three UV-Vis absorption bands increase rapidly with exposure time at 232, 284 and $333 \mathrm{~nm}$.

Fig. 3 compares the UV-Vis spectra of PVAl films after a relatively similar timeframe of thermal exposure in air at 70, 90 and $100{ }^{\circ} \mathrm{C}$, typically ranging from 303 to 345 days. It can be observed that the absorbance of the three bands under consideration increases with the aging temperature. This results implies that the thermal aging of HT-PVAl is thermo-activated. 

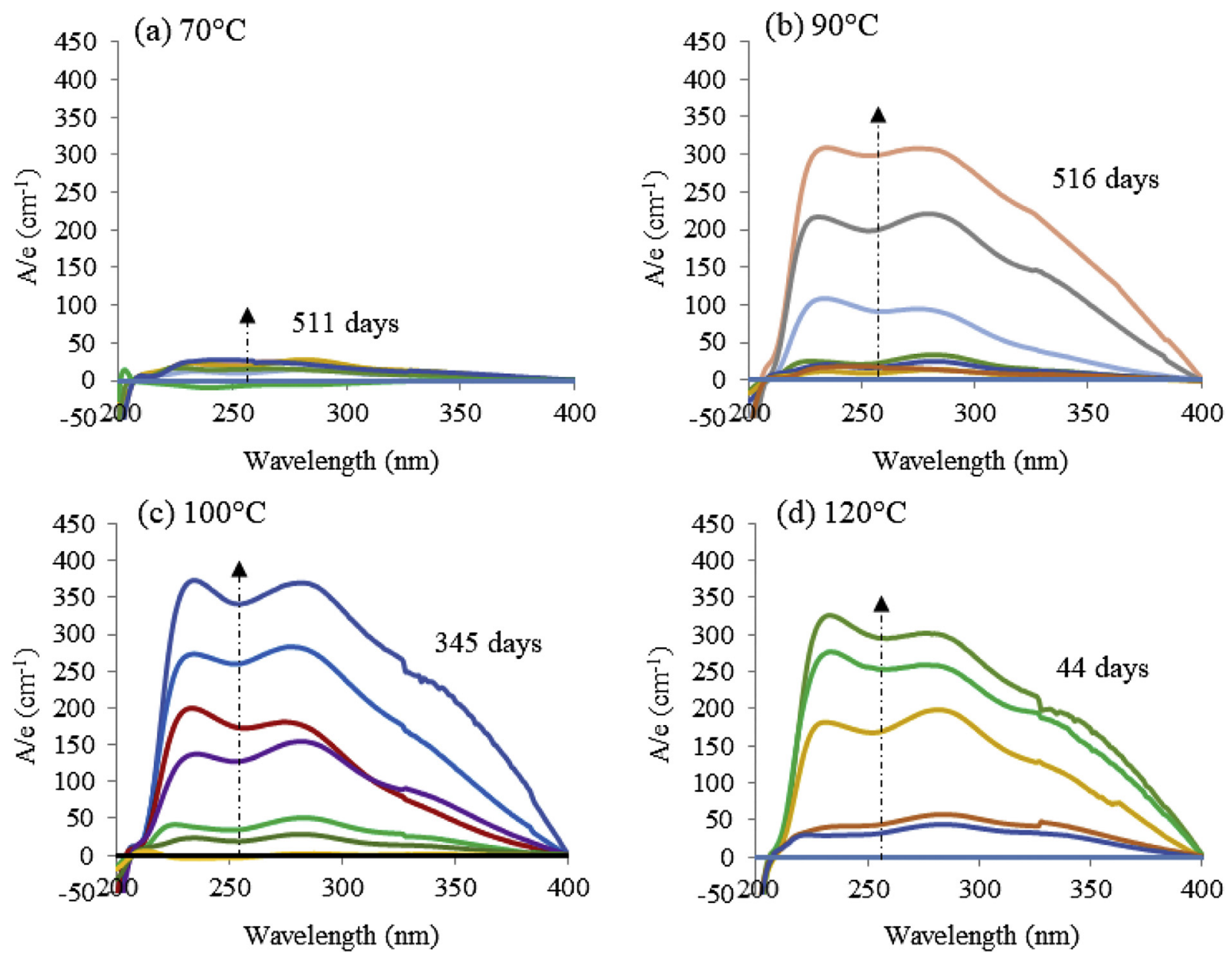

Fig. 2. Changes (normalized by the film thickness) in the UV-Vis spectrum of PVAl films after thermal exposure in air at (a) $70{ }^{\circ} \mathrm{C}$, (b) $90{ }^{\circ} \mathrm{C}$, (c) $100{ }^{\circ} \mathrm{C}$, and (d) $120{ }^{\circ} \mathrm{C}$.

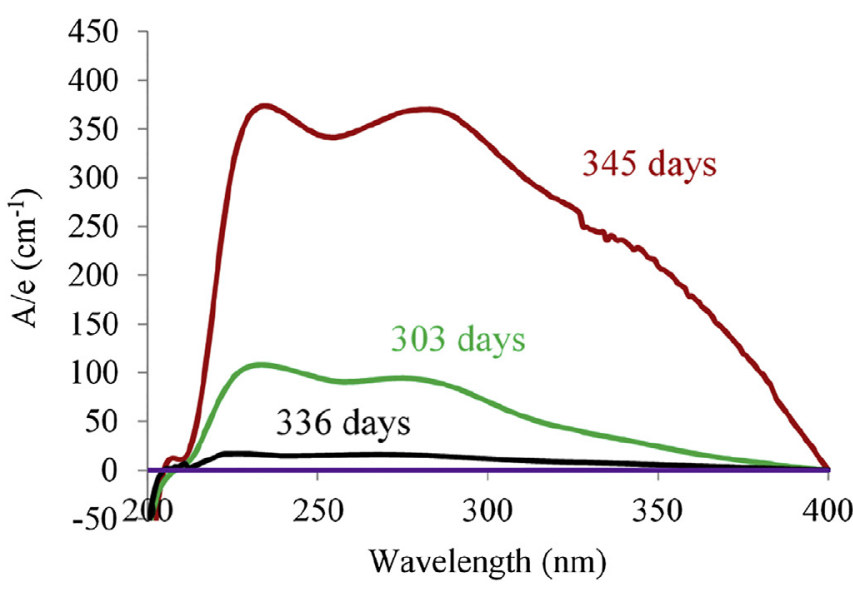

Fig. 3. Comparison between the UV-Vis spectra of PVAl films before (violet) and after an almost identical period of thermal exposure in air at $70{ }^{\circ} \mathrm{C}$ (black), $90^{\circ} \mathrm{C}$ (green) and $100{ }^{\circ} \mathrm{C}$ (red). (For interpretation of the references to colour in this figure legend, the reader is referred to the Web version of this article.)

In the literature [14-16], the appearance of the three absorption bands at 232, 284 and $333 \mathrm{~nm}$ on the UV-Vis spectrum is attributed to the formation of unsaturated structures of polyenone and polyene type. Polyenones, whose general formula is $-(\mathrm{CH}=\mathrm{CH})_{\mathrm{n}-1^{-}}$ CO-, contain isolated or conjugated carbon-carbon double bonds connected with a carbonyl group such as aldehyde, ketone, carboxylic acid or ester. In contrast, polyenes, whose general formula is $-(\mathrm{CH}=\mathrm{CH})_{n^{-}}$, consist only in conjugated carbon-carbon double bonds. Table 1 lists all the polyenone and polyene structures susceptible to be formed during the thermal aging of HT-PVAl [15].

The UV-Vis absorption band at $232 \mathrm{~nm}$ is attributed to the formation of unsaturated structures with $n=2$. The corresponding degradation products are numerous, but all present two conjugated double bonds, i.e. either two $\mathrm{C}=\mathrm{C}$ in the case of polyenes, or one $\mathrm{C}=\mathrm{C}$ and one $\mathrm{C}=\mathrm{O}$ in the case of polyenones.

Similarly, the absorption band at $284 \mathrm{~nm}$ is attributed to the formation of unsaturated structures having three conjugated double bonds $(\mathrm{n}=3)$. Finally, the absorption band at $333 \mathrm{~nm}$ is attributed to the formation of unsaturated structures having four conjugated double bonds $(n=4)$.

According to Table 1, each UV-Vis absorption band corresponds to a mixture of polyene and polyenone structures. In addition, there is a wide variety of possible polyenone structures: unsaturated aldehyde, ketone, carboxylic acid or ester. Only the orders of magnitude of their molar extinction coefficient are known. For all these reasons, it is not possible to precisely calculate the concentration of each type of polyene and polyenone structure absorbing in the UV-Vis range using the Beer-Lambert's law. However, it is possible to get a rough idea about the relative predominance of the different levels of conjugation (i.e. $\mathrm{n}=2,3$ and 4 ) during the thermal aging of HT-PVAl yarns. 
Table 1

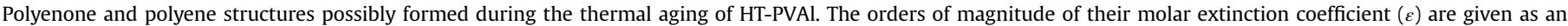
indication in the last line $[15,17-20]$.

\begin{tabular}{|c|c|c|c|c|}
\hline Wavelength & & $232 \mathrm{~nm}$ & $284 \mathrm{~nm}$ & $333 \mathrm{~nm}$ \\
\hline \multirow[t]{5}{*}{ Attribution } & Polyenone $-(\mathrm{CH}=\mathrm{CH})_{\mathrm{n}-1}-\mathrm{CO}-=$ & $\mathrm{R}-\mathrm{CH}=\mathrm{CH}-\mathrm{COH}$ & $\mathrm{R}-(\mathrm{CH}=\mathrm{CH})_{2}-\mathrm{COH}$ & $\mathrm{R}-(\mathrm{CH}=\mathrm{CH})_{3}-\mathrm{COH}$ \\
\hline & & $\mathrm{R}-\mathrm{CH}=\mathrm{CH}-\mathrm{CO}-\mathrm{R}$ & $\mathrm{R}-(\mathrm{CH}=\mathrm{CH})_{2}-\mathrm{CO}-\mathrm{R}$ & $\mathrm{R}-(\mathrm{CH}=\mathrm{CH})_{3}-\mathrm{CO}-\mathrm{R}$ \\
\hline & & $\mathrm{R}-\mathrm{CH}=\mathrm{CH}-\mathrm{COOH}$ & $\mathrm{R}-(\mathrm{CH}=\mathrm{CH})_{2}-\mathrm{COOH}$ & $\mathrm{R}-(\mathrm{CH}=\mathrm{CH})_{3}-\mathrm{COOH}$ \\
\hline & & $\mathrm{R}-\mathrm{CH}=\mathrm{CH}-\mathrm{COOR}$ & $\mathrm{R}-(\mathrm{CH}=\mathrm{CH})_{2}-\mathrm{COOR}$ & $\mathrm{R}-(\mathrm{CH}=\mathrm{CH})_{3}-\mathrm{COOR}$ \\
\hline & Polyene $-(\mathrm{CH}=\mathrm{CH})_{\mathrm{n}}-$ & $\mathrm{R}-(\mathrm{CH}=\mathrm{CH})_{2}-\mathrm{R}$ & $\mathrm{R}-(\mathrm{CH}=\mathrm{CH})_{3}-\mathrm{R}$ & $\mathrm{R}-(\mathrm{CH}=\mathrm{CH})_{4}-\mathrm{R}$ \\
\hline Nature & & 2 conjugated double bonds & 3 conjugated double bonds & 4 conjugated double bonds \\
\hline$\varepsilon\left(\right.$ in L. $\left.\mathrm{mol}^{-1} \cdot \mathrm{cm}^{-1}\right)$ & & 23000 & 40000 & 70000 \\
\hline
\end{tabular}

Fig. 4 shows the changes in the absorbance (normalized by the film thickness) of unsaturated structures at 232, 284 and $333 \mathrm{~nm}$ with exposure time in air between 70 and $120{ }^{\circ} \mathrm{C}$. These results illustrate well our previous observations. First of all, the thermal degradation kinetics of HT-PVAl is thermo-activated since the absorbance is an increasing function of temperature. Besides, the absorbance of unsaturated structures at $333 \mathrm{~nm}$ is lower than those at 284 and $232 \mathrm{~nm}$, which means that unsaturated structures with a conjugation degree higher than 3 are formed with high difficulty.

The relative proportions (in $\mathrm{mol} \%$ ) of unsaturated structures at 232, 284 and $333 \mathrm{~nm}$ were calculated from absorbance ratios (see Table 2). Thanks to these values, it can be concluded that structures
Table 2

Relative proportions (in mol\%) of unsaturated structures at 232, 284 and $333 \mathrm{~nm}$ during the thermal aging of HT-PVAl yarns in air between 90 and $120{ }^{\circ} \mathrm{C}$.

\begin{tabular}{lllll}
\hline Wavenumber $\left(\mathrm{cm}^{-1}\right)$ & Level of conjugation & \multicolumn{2}{l}{ Temperature } \\
\cline { 3 - 5 } & & $90{ }^{\circ} \mathrm{C}$ & $100{ }^{\circ} \mathrm{C}$ & $120{ }^{\circ} \mathrm{C}$ \\
\hline $232 \mathrm{~nm}$ & $\mathrm{n}=2$ & 55 & 56 & 56 \\
$284 \mathrm{~nm}$ & $\mathrm{n}=3$ & 34 & 34 & 34 \\
$333 \mathrm{~nm}$ & $\mathrm{n}=4$ & 11 & 10 & 10 \\
\hline
\end{tabular}

with only two conjugated double bonds ( $\mathrm{n}=2$ at $232 \mathrm{~nm}$ ) largely predominate over other unsaturated structures $(\mathrm{n}=3$ at $284 \mathrm{~nm}$
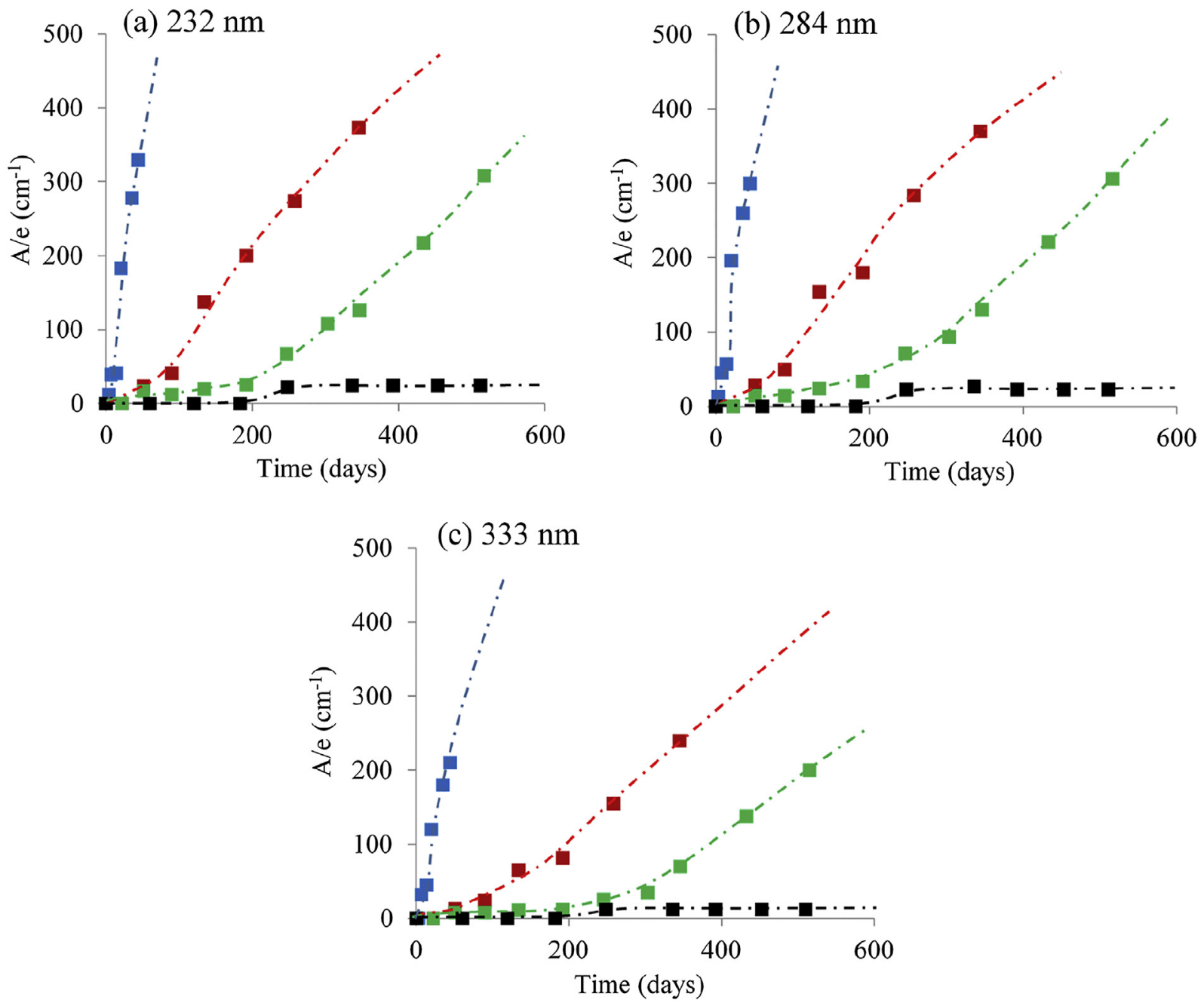

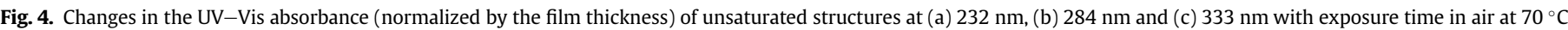

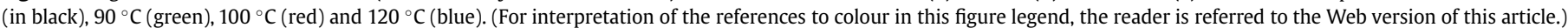




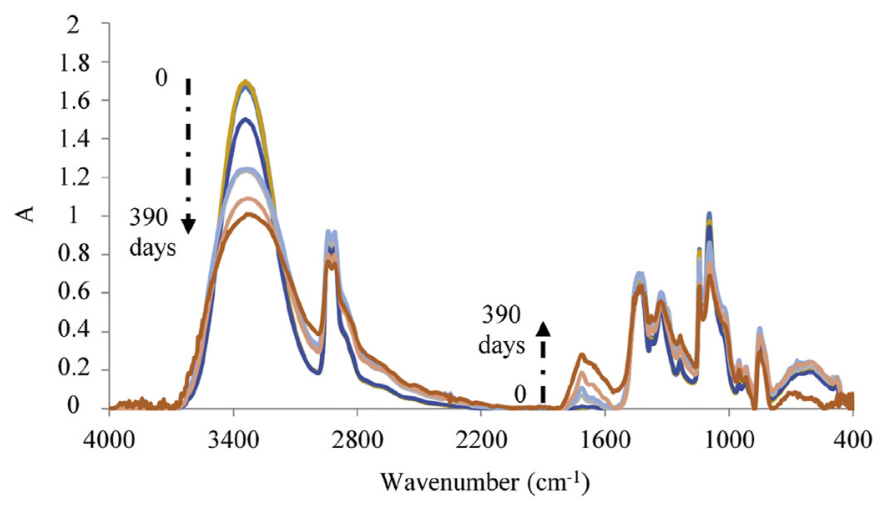

Fig. 5. Changes in the IR spectrum of PVAl films after thermal exposure in air at $100{ }^{\circ} \mathrm{C}$.

and $\mathrm{n}=4$ at $333 \mathrm{~nm}$ ) at all exposure temperatures, meaning that it is more difficult to form unsaturated structures with a higher degree of conjugation. These results will be supplemented by those obtained through another spectrochemical technique, FTIR spectrometry, in the next paragraph in order to elucidate the thermal aging mechanism of HT-PVAl yarns.

\subsubsection{FTIR spectrometry}

The PVAl films produced from HT-PVAl yarns after thermal (in air at $70,90,100$ and $120{ }^{\circ} \mathrm{C}$ ) were also analyzed by FTIR spectroscopy in a transmission mode. As an example, Fig. 5 shows the changes in the IR spectrum of PVAl films during the first 390 days of thermal exposure in air at $100{ }^{\circ} \mathrm{C}$. It can be observed that thermal aging generates two major changes on the FTIR spectrum: i) A decrease of the absorption band at $3340 \mathrm{~cm}^{-1}$, implying the consumption of hydroxyl groups (i.e. alcohols); ii) The growth of several IR absorption bands located between 1550 and $1800 \mathrm{~cm}^{-1}$ often attributed to carbonyls and carbon-carbon double bonds.

A focus in the spectral range from 1550 to $1800 \mathrm{~cm}^{-1}$ is given in Fig. 6 (a). Several IR absorption bands are overlapped in this area, making it difficult to determine their exact absorbance and wavelength. To separate the elementary contribution of each absorption band, a mathematical deconvolution was performed using Gaussian functions. Fig. 6 (b) shows an example of deconvolution for a PVAl sample aged for 345 days in air at $100^{\circ} \mathrm{C}$. Six absorption bands were detected and identified. They are located at 1757, 1737, $1712,1656,1630$ and $1592 \mathrm{~cm}^{-1}$. It can be seen that the absorption bands at 1656 and $1712 \mathrm{~cm}^{-1}$ are the most intense. The former is attributed to isolated carbon-carbon double bonds [21], while the latter can be attributed to unsaturated and saturated ketones and carboxylic acids according to the literature data compiled in Table 3.

The assignment of the other four IR absorption bands put in evidenced by the mathematical deconvolution is also given in Table 3. It should be noted that the assignment of the absorption band at $1757 \mathrm{~cm}^{-1}$ to esters was not fully demonstrated because, in the literature, the formation of esters in linear structures is rather detected around $1730-1750 \mathrm{~cm}^{-1}[24,27]$, while the formation of esters in cyclic structures is rather detected around $1770-1790$ $\mathrm{cm}^{-1}[22,23]$. In fact, these latter correspond to five-membered rings well known as $\gamma$ lactones. There are also larger and thus less strained cyclic structures, such as six-membered rings (or $\delta$ lactones), but their absorption band is shifted at the same wavenumbers as linear structures (i.e. around $1730-1750 \mathrm{~cm}^{-1}$ ) [25]. Based on this brief literature analysis, it would seem that the absorption band at $1757 \mathrm{~cm}^{-1}$ can only be assigned to unsaturated $\gamma$ lactones, but this assumption remains to be proven and the contribution of other types of carbonyl groups cannot be totally excluded.
To confirm the presence of esters at $1757 \mathrm{~cm}^{-1}$ as well as the presence of carboxylic acids at $1712 \mathrm{~cm}^{-1}$, a chemical derivatization, consisting in exposing aged samples to ammonia gas at room temperature for one week (see details in Section 2.4), was performed and new FTIR spectra were acquired.

Fig. 7 (a) shows the IR spectrum before and after ammonia gas treatment for a PVAl sample aged for 345 days in air at $100{ }^{\circ} \mathrm{C}$. First of all, it can be observed that the absorption band at $1757 \mathrm{~cm}^{-1}$ has completely disappeared while a new absorption band has appeared at $1670 \mathrm{~cm}^{-1}$ after chemical treatment. This new absorption band is assigned to primary amides whose general formula is $\mathrm{R}-\mathrm{CONH}_{2}$. Thus, this first result confirms the presence of esters in the aged samples. Then, it can be observed that the absorption band at 1712 $\mathrm{cm}^{-1}$ has strongly decreased in intensity while a new absorption band has appeared at $1580 \mathrm{~cm}^{-1}$ after chemical treatment. This latter is characteristic of carboxylate ions $\mathrm{R}-\mathrm{COO}^{-}$. This second result confirms the presence of carboxylic acids in the aged samples. Finally, the presence of ketones $\mathrm{R}-\mathrm{CO}-\mathrm{R}$ in the aged samples is also confirmed due to the presence of a small shoulder at 1707 $\mathrm{cm}^{-1}$ in the IR spectrum obtained after chemical treatment. Indeed, as expected, these latter do not react with $\mathrm{NH}_{3}$.

The wavenumber and absorbance of the IR band of carboxylic acids were precisely determined by subtracting the spectrum obtained after chemical treatment to the spectrum obtained before chemical treatment, as shown in Fig. 7 (b). The negative part represents the absorption bands of esters and carboxylic acids (at 1757 and $1720 \mathrm{~cm}^{-1}$ respectively) that have disappeared during chemical treatment, whereas the positive part represents the absorption bands of the primary amides and carboxylate ions (at 1670 and $1580 \mathrm{~cm}^{-1}$ respectively) that have been formed during chemical treatment.

Table 4 reports the full list of the degradation products formed and identified during the thermal aging of HT-PVAl yarns. As previously explained, the IR absorption band detected at $1712 \mathrm{~cm}^{-1}$ in Fig. 7 (b) is the result of two elementary contributions at 1720 and $1707 \mathrm{~cm}^{-1}$, attributed to carboxylic acids and ketones respectively.

The concentration of the different chemical products consumed or formed during the thermal aging of HT-PVAl yarns was determined from the absorbance of their characteristic IR absorption band using the classical Beer-Lambert's law. The values proposed in the literature for the molar extinction coefficients were chosen for this calculation (see Table 3): $\varepsilon=720,680,300$ and $37 \mathrm{~L} \cdot \mathrm{mol}^{-1} \cdot \mathrm{cm}^{-1}$ for (cyclic) esters, carboxylic acids, ketones and (isolated or conjugated) carbon-carbon double bonds, respectively.

Fig. 8 shows the concentration changes of alcohols, isolated carbon-carbon double bonds, conjugated carbon-carbon double bonds, polyenones, aldehydes, ketones, carboxylic acids and esters during the thermal aging of HT-PVAl yarns in air between 70 and $120^{\circ} \mathrm{C}$. Alcohol functions are progressively consumed while several degradation products are formed whose concentrations vary in the following order:

Isolated carbon-carbon double bonds $>$ Conjugated carbon-carbon double bonds $\geq$ Polyenones $>$ Aldehydes $\geq$ Ketones $>$ Carboxylic acids $\geq$ Esters

This relative order agrees well with the observations of Aoki et al. [24] who studied PVAl oxidation under UV irradiation. The concentrations of carboxylic acids and esters are much lower than the concentrations of all other degradation products and thus might be, in a first approximation, ignored.

\subsubsection{Mechanistic interpretations}

Based on the oxidation mechanisms proposed for PVAl under UV radiation [16, 24] and in aqueous alkaline solution [37], but also 

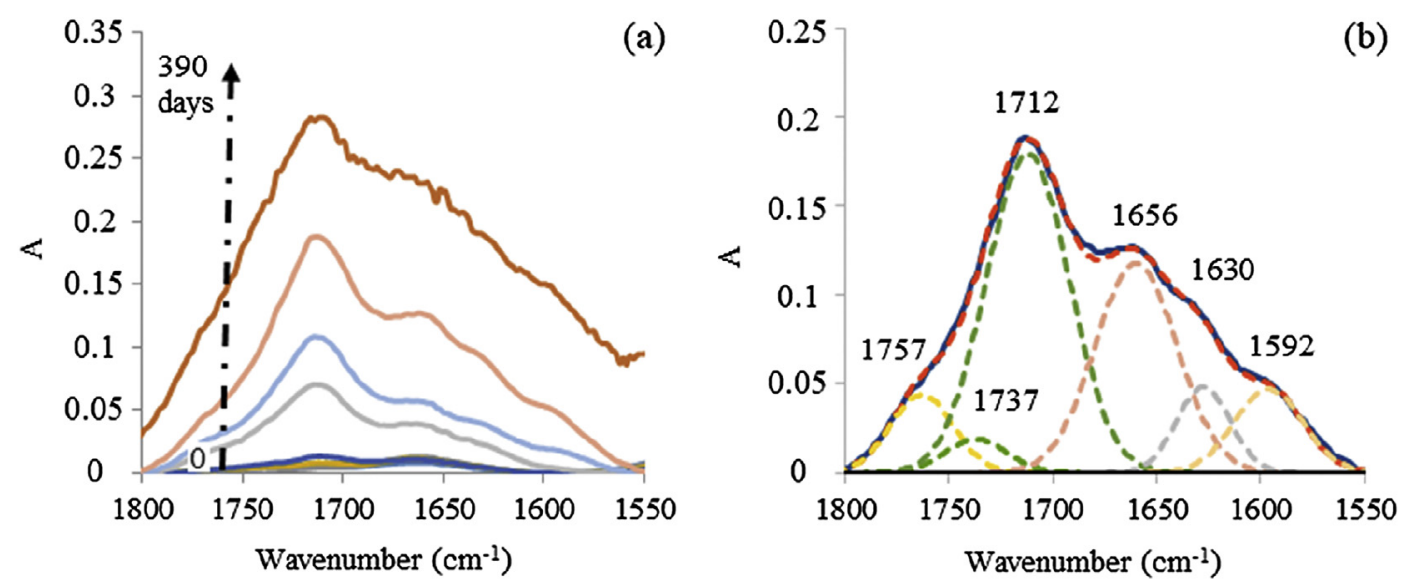

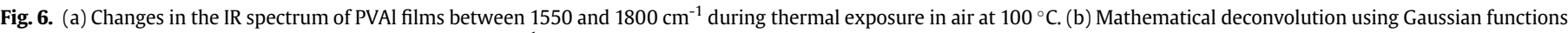
of the FTIR spectrum obtained between 1550 and $1800 \mathrm{~cm}^{-1}$ for a PVAl film aged for 345 days in air at $100{ }^{\circ} \mathrm{C}$.

Table 3

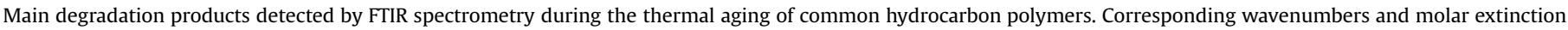
coefficients.

\begin{tabular}{|c|c|c|}
\hline Chemical groups & Wavenumber $\left(\mathrm{cm}^{-1}\right)$ & Molar extinction coefficient $\left(\mathrm{L} \cdot \mathrm{mol}^{-1} \cdot \mathrm{cm}^{-1}\right)$ \\
\hline Hydroxyls & $3100-3600[16,21]$ & $70[26,27]$ \\
\hline$\gamma$ Lactones & $1780-1790[22,23]$ & $720[22]$ and $825[23]$ \\
\hline Esters & $1738[24]$ and $1746[28]$ & $590[10,29]$ and $450[28]$ \\
\hline Aldehydes & $1736[28]$ & $155[28]$ \\
\hline Carbonyls & $1715-1730[4,21,30]$ & $200[26]$ and $300[27]$ \\
\hline Saturated ketones & $1717-1725[16]$ & $300[28,31]$ \\
\hline Unsaturated ketones & $1705[32]$ and $1709[24]$ & $300[31]$ \\
\hline Saturated carboxylic acids & $1715[16]$ & $680[28]$ \\
\hline Unsaturated carboxylic acids & $1700[24]$ & $680[28]$ \\
\hline Isolated carbon-carbon double bonds & $1639-1661[33], 1640[21,32], 1650$ [34] and 1664 [35] & 37 and 38 [33] \\
\hline Conjugated carbon-carbon double bonds & $1573[36], 1580$ [34], 1593 [35], 1595 [30] and 1628 [35] & No available data \\
\hline
\end{tabular}
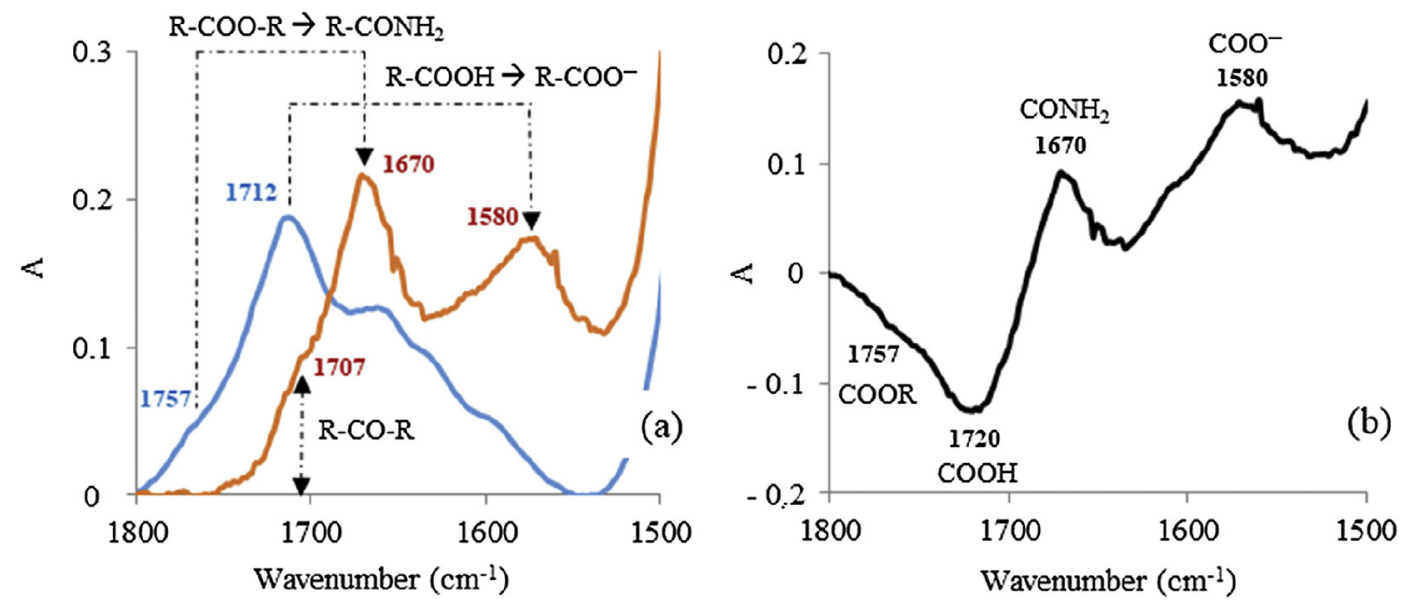

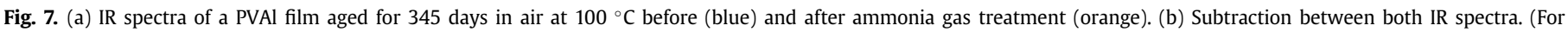
interpretation of the references to colour in this figure legend, the reader is referred to the Web version of this article.)

for PVC under UV radiation [34], it is possible to build the general thermo-oxidation mechanistic scheme presented in Fig. 9. This scheme explains the formation of almost all the degradation products identified in HT-PVAl yarns.

This mechanistic scheme presents the following features:

i) Oxidation is a radical chain reaction preferentially occurring on the carbon atom of the monomer unit carrying the most labile hydrogen atom. Recall that the dissociation energy $E_{D}$ of $\mathrm{C}-\mathrm{H}$ bond is lower for a tertiary carbon $\mathrm{C}_{\mathrm{t}}$ $\left(E_{D} \approx 378 \mathrm{~kJ} \mathrm{~mol}^{-1}\right)$ than for a secondary carbon $C_{S}$ $\left(\mathrm{E}_{\mathrm{D}} \approx 393 \mathrm{~kJ} \mathrm{~mol}^{-1}\right)$ [38]. In addition, the dissociation energy of $\mathrm{C}-\mathrm{H}$ bond is further lowered by about $10-20 \mathrm{~kJ} \mathrm{~mol}^{-1}$ when the carbon atom is directly linked to a heteroatom, e.g. a nitrogen or oxygen atom $[38,39]$. For these reasons, the oxidation of PVAl preferentially occurs on the tertiary carbon 
Table 4

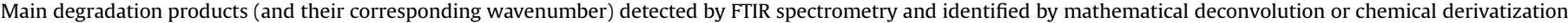
during the thermal aging of HT-PVAl yarns.

\begin{tabular}{|c|c|c|c|}
\hline Wavenumber $\left(\mathrm{cm}^{-1}\right)$ & Attribution & Chemical formula & Determination method \\
\hline 1757 & Esters & $\mathrm{R}-\mathrm{COO}-\mathrm{R}$ & Mathematical deconvolution \\
\hline 1737 & Aldehydes & $\mathrm{R}-\mathrm{CHO}$ & Mathematical deconvolution \\
\hline 1712 & Carboxylic acids and ketones & $\mathrm{R}-\mathrm{COOH}$ and $\mathrm{R}-\mathrm{CO}-\mathrm{R}$ & Mathematical deconvolution \\
\hline 1720 & Carboxylic acids & $\mathrm{R}-\mathrm{COOH}$ & Chemical derivatization \\
\hline 1707 & Ketones & $\mathrm{R}-\mathrm{CO}-\mathrm{R}$ & Chemical derivatization \\
\hline 1656 & Isolated carbon-carbon double bonds & $\mathrm{R}-\mathrm{CH}=\mathrm{CH}-\mathrm{R}$ & Mathematical deconvolution \\
\hline 1630 & Polyenones & $\mathrm{R}-(\mathrm{CH}=\mathrm{CH})_{\mathrm{n}-1}-\mathrm{CO}-\mathrm{R}$ & Mathematical deconvolution \\
\hline 1592 & Conjugated carbon-carbon double bonds & $\mathrm{R}-(\mathrm{CH}=\mathrm{CH})_{\mathrm{n}}-\mathrm{R}$ & Mathematical deconvolution \\
\hline
\end{tabular}

$\mathrm{C}_{\mathrm{t}}$ carrying the alcohol function, as shown in Fig. 8. The resulting alkyl radicals $\mathrm{P}^{\bullet}$ are responsible for the propagation of oxidation along the polymer chain, thus generating unstable hydroperoxides $\mathrm{POOH}$ whose unimolecular decomposition leads to the formation of alkoxy radicals $\mathrm{PO}^{\bullet}$. The rapid rearrangement by $\beta$ scission of these latter allows explaining the formation of two major carbonyl products: carboxylic acids and ketones. Of course, $\beta$ scission is in competition with hydrogen abstraction, which generates diols.

ii) In addition, it is suspected that this unimolecular $\mathrm{POOH}$ decomposition is catalyzed by acids, as already proposed for polyolefins [40, 41]. Indeed, the bimolecular recombination of carboxyl radicals with alkyl radicals would explain the formation of another type of major carbonyl product: esters (Fig. 10). Of course, this recombination is also in competition with hydrogen abstraction, which regenerates carboxylic acids.

iii) The formation of carbon-carbon double bonds is driven by the elimination of alcohol side groups under the form of water molecules. For this reason, this reaction is commonly called "dehydration" in the literature [21, 30, 42]. According to the mechanistic scheme of Fig. 11, the formation of a first double bond would strongly destabilize the next monomer unit and so on, triggering a sequential (or "zip") elimination of water molecules, that would finally lead to the formation of the observed polyene structures. By analogy with the PVC dehydrochlorination [38], the presence of any structural irregularity (noted S) in the PVAl chain (e.g. double bond, diol, ketone, etc.) would strongly destabilize the neighbor monomer unit. Thus, the sequential elimination induced by ketones would partly explain the formation of polyenone structures.

To check the relevance of the dehydration mechanistic scheme proposed in Fig. 11, the concentrations of $\mathrm{OH}$ functions lost and carbon-carbon double bonds formed during the thermal aging of HT-PVAl yarns were determined using the Beer-Lambert's law. The concentration of lost $\mathrm{OH}$ functions was calculated from the absorbance decrease of the IR band at $3400 \mathrm{~cm}^{-1}$. In parallel, the concentration of formed double bonds was calculated form the absorbance increase of the IR bands at $1656 \mathrm{~cm}^{-1}$ (for isolated carbon-carbon double bonds), $1592 \mathrm{~cm}^{-1}$ (for conjugated carboncarbon double bonds) and $1630 \mathrm{~cm}^{-1}$ (for polyenones) using the relative proportions of the different conjugation degrees reported in Table 2. Fig. 12 compares the concentration of $\mathrm{OH}$ functions lost with the total concentration of double bonds formed during the thermal aging of HT-PVAl yarns in air between 70 and $120^{\circ} \mathrm{C}$. For all exposure conditions, both concentrations are very close, that constitutes an important proof in favor of this mechanistic scheme. Indeed, according to this latter, the loss of one $\mathrm{OH}$ function would lead to the formation one carbon-carbon double bond. In other words, the concentration of $\mathrm{OH}$ functions lost should correspond to the total concentration of double bonds formed during the thermal aging of HT-PVAl yarns. It can be thus concluded that the validity of the proposed dehydration mechanism is successfully checked. It should be underlined that this result also supports the conclusion that the thermal aging of PVAl leads to the formation and accumulation of carbonyl groups (essentially aldehydes and ketones) rather than hydroxyl groups (i.e. diols and carboxylic acids).

However, it must be recalled that UV-Vis spectrometry clearly indicates that unsaturated structures with a high degree of conjugation are formed with difficulty in HT-PVAl yarns. Indeed, the maximum conjugation degree observed is $n=4$ (Table 1 ). In addition, structures with only two conjugated double bonds largely predominate over other unsaturated structures, whatever the exposure conditions (Table 2). This behavior can be explained by the high oxidability of allyl $\mathrm{C}-\mathrm{H}$ bonds whose dissociation energy is only $\mathrm{E}_{\mathrm{D}} \approx 335 \mathrm{~kJ} \mathrm{~mol}^{-1}$ [38]. Indeed, it can be seen in Fig. 13 that the oxidation of the allylic methylene of the neighbor monomer unit will stop the propagation of the dehydration reaction. Thus, it can be concluded that in PVAl, oxidation does not only initiate the dehydration reaction, due to the formation of new structural irregularities in the PVAl chain, but also it annihilates the propagation step of dehydration by rapidly consuming allylic methylenes.

The oxidation of allylic methylenes allows explaining the formation of the last major carbonyl product: aldehydes. It should be noted that aldehydes are extremely oxidizable products, and even more if they are unsaturated aldehydes. Indeed, as mentioned before, the presence of an oxygen atom in a close vicinity lowers the dissociation energy of the $\mathrm{C}-\mathrm{H}$ bond of about $10-20 \mathrm{~kJ} \mathrm{~mol}^{-1}[38$, 39]. Therefore, aldehydes will quickly be converted into secondary oxidation products such as carboxylic acids or esters, according to the mechanistic scheme summarized in Fig. 14.

Finally, due to the high concentration in $\mathrm{OH}$ functions in this material, it is suspected that part of the carboxylic acids condenses with alcohols to form esters. As shown in Fig. 15, if intramolecular, this reaction could then explain the formation of unsaturated $\gamma$ lactones supposed to be detected at $1757 \mathrm{~cm}^{-1}$ in IR spectra (see Fig. 6).

\subsection{Changes from the macromolecular to macroscopic scale}

The consequences of the chemical modifications (evidenced in the previous Section 3.1) at the upper scales were analyzed through the macromolecular structure, humid behavior, crystalline morphology and mechanical behavior of HT-PVAl yarns. Recall that, before any physico-chemical and mechanical characterization, all the samples were stored for at least two weeks in an airconditioned room (at $22{ }^{\circ} \mathrm{C}$ in $50 \% \mathrm{RH}$ ) in order to reduce as much as possible the experimental scattering. 

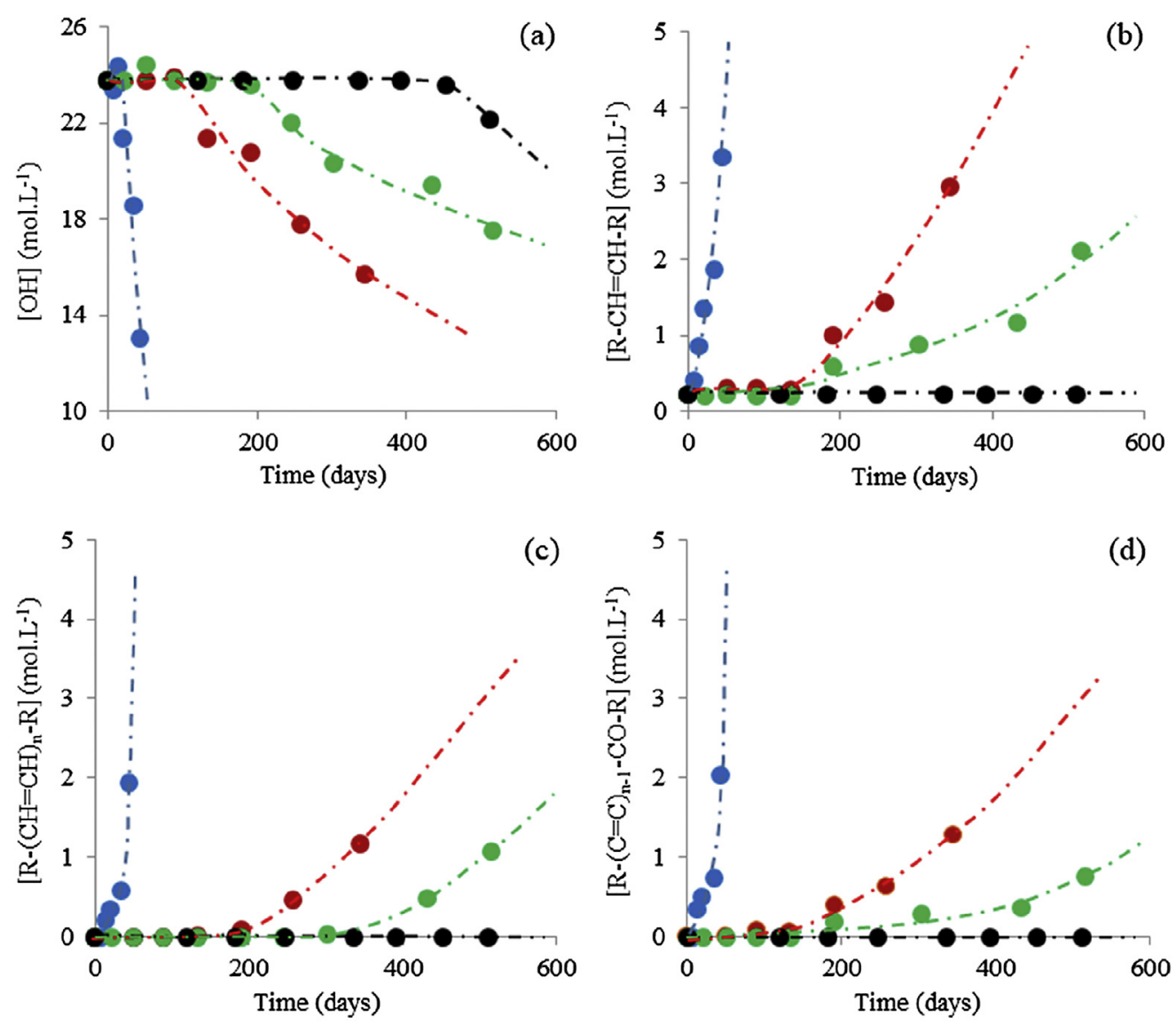

(e)
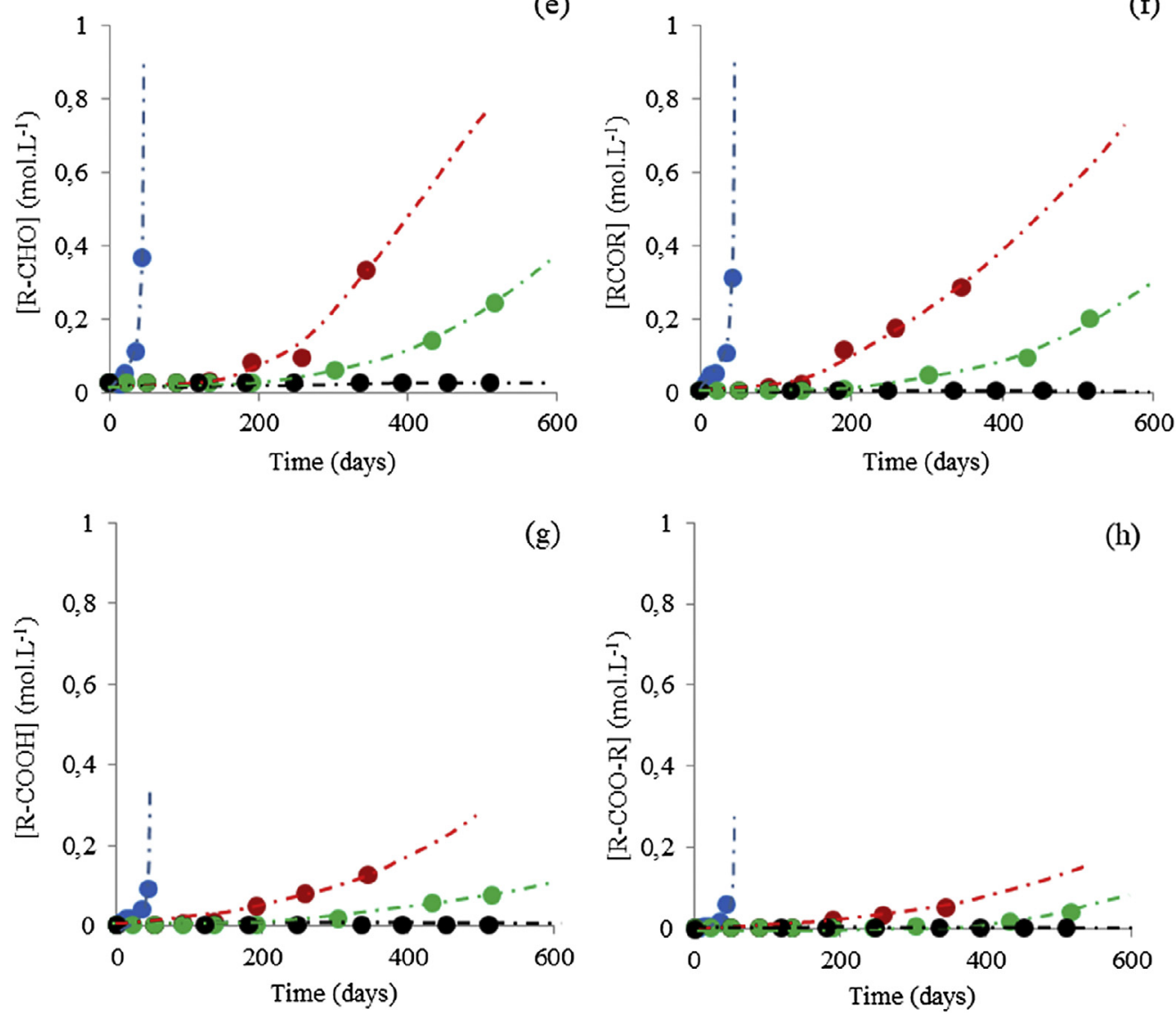

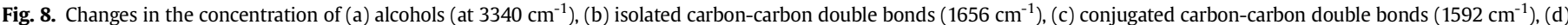

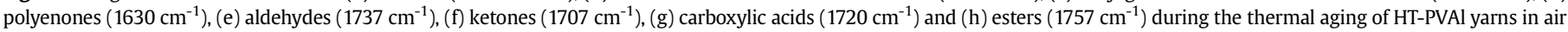

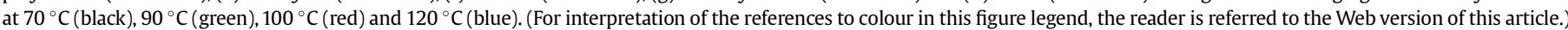



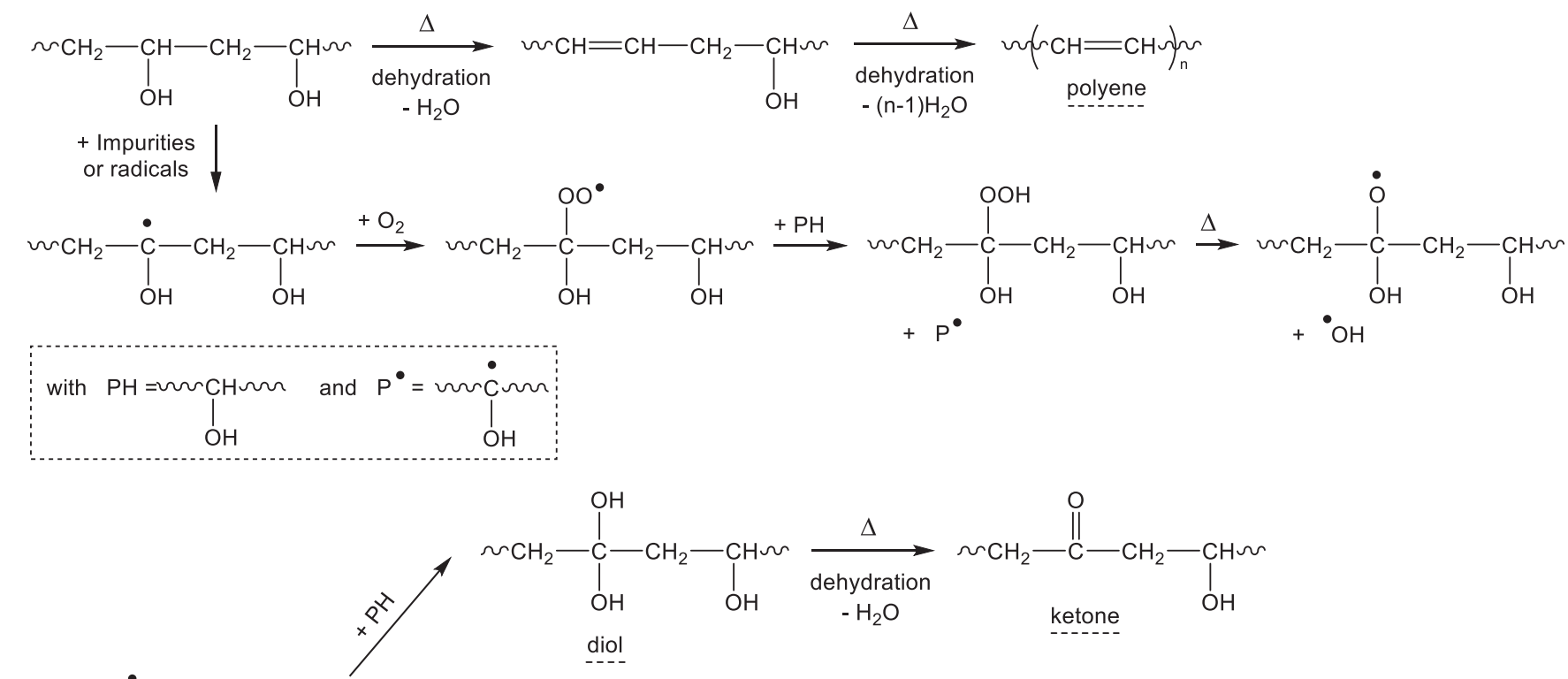<smiles>CCC(O)(O)CC(O)O</smiles>
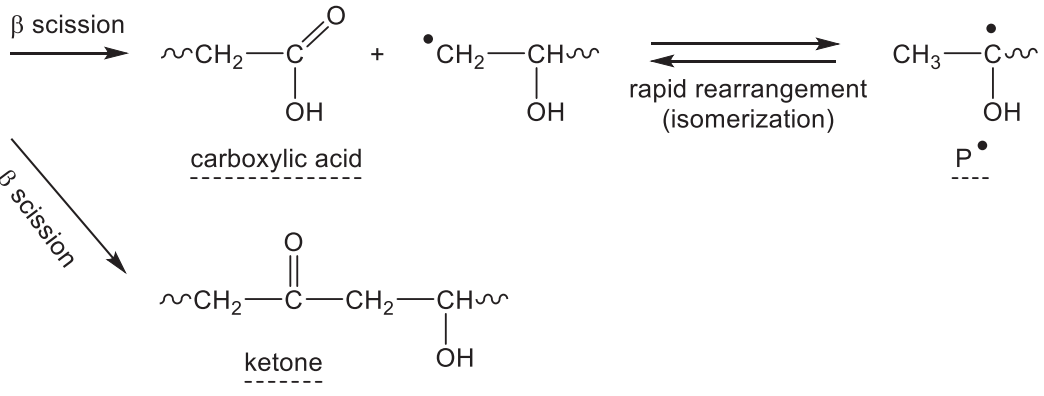<smiles>CCC(=O)CC(O)CC</smiles><smiles>CC(C)CC(C)C</smiles>

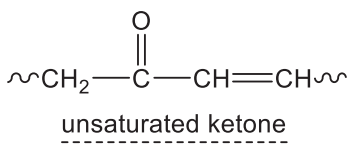<smiles>CC(C)C(O)C(C)C</smiles><smiles>CC=CC(=O)C(C)CC</smiles>

Fig. 9. Proposal of mechanistic scheme for the thermal aging of PVAl. Oxidation preferentially occurs on tertiary carbon $\mathrm{C}_{\mathrm{t}}$ carrying the alcohol function.

\subsubsection{Macromolecular structure and humid behavior of the amorphous phase}

Fig. 16 shows the changes in the glass transition temperature $\left(\mathrm{T}_{\mathrm{g}}\right)$ and the equilibrium water content $\left(\mathrm{W}_{\mathrm{S}}\right)$ of HT-PVAl yarns with exposure time in air between 70 and $120^{\circ} \mathrm{C}$. It can be seen that both properties remain of the same order of magnitude as their initial value (no visible change) during thermal aging, with an average $T_{g}$ around $53{ }^{\circ} \mathrm{C}$ and an equilibrium water content around $1.8 \mathrm{wt} \%$.

Moreover, sorption experiments were carried out at $60^{\circ} \mathrm{C}$ under different relative humidities (typically ranging between $15 \%$ and 90\% RH) on HT-PVAl yarns before and after 345 days of thermal exposure in air at $100{ }^{\circ} \mathrm{C}$. Then, the corresponding equilibrium water contents were plotted versus relative humidity in Fig. 17 to obtain the so-called sorption isotherms. These two curves display two consecutive behaviors. Up to about $50 \% \mathrm{RH}$, WS increases linearly with relative humidity, thus characterizing a classical Henry's behavior [43]. However, between 50 and $100 \% \mathrm{RH}$, the increase in $\mathrm{W}_{\mathrm{S}}$ gradually accelerates, thus showing a positive concavity which corresponds to a Flory-Huggins' behavior [43]. This positive concavity is generally attributed to the formation of water clusters in the literature $[44,45]$. In addition, no difference is observed between the sorption isotherms of the unaged and aged samples.
Thus, even at high conversion ratios, thermal aging does not modify either the nature or the intensity of the water-polymer interactions in HT-PVAl yarns.

Following this first series of analyses, it can be concluded that the amorphous phase of HT-PVAl yarns does not seem to be affected by the thermal aging. These results will be supplemented by those obtained on the crystalline phase in the next paragraph in order to get an overall view of the microstructural changes occurring in HT-PVAl yarns.

\subsubsection{Crystalline morphology}

As an example, Fig. 18 shows the changes in the melting peak of HT-PVAl yarns during their thermal exposure in air at $100^{\circ} \mathrm{C}$. It can be observed that this peak is progressively shifted towards lower temperatures, while the area under the peak gradually decreases with exposure time. Taking a closer look at the melting peak of the unaged sample, it appears that it is composed of two contributions: a primary component centered at $239{ }^{\circ} \mathrm{C}$ and a secondary one centered at $241^{\circ} \mathrm{C}$. In fact, the contribution of the secondary component gradually decreases with exposure time to finally vanish. These results indicate that, contrarily to the amorphous phase, the crystalline phase of HTPVAl yarns is strongly affected by the thermal aging. 


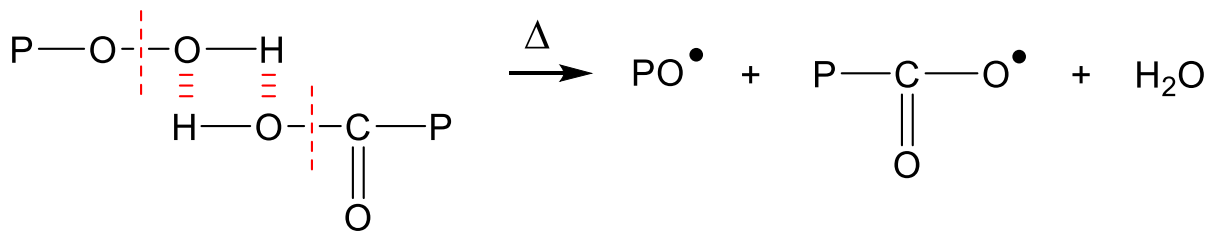<smiles>O=C(P)O[CH+]P[PH3+]</smiles>

\section{ester}<smiles>[CH2+]OC(=O)PC=P[18OH]</smiles>

carboxylic acid

Fig. 10. Hydroperoxide decomposition catalyzed by acids [37, 38].

Fig. 19 shows the changes in the melting temperature $\left(\mathrm{T}_{\mathrm{m}}\right)$ and crystallinity ratio $\left(\mathrm{X}_{\mathrm{c}}\right)$ of HT-PVAl yarns during their thermal exposure in air between 70 and $120^{\circ} \mathrm{C}$. Above $90{ }^{\circ} \mathrm{C}, \mathrm{T}_{\mathrm{m}}$ and $\mathrm{X}_{\mathrm{c}}$ gradually decrease with exposure time after an induction period. The induction period and the decay rate of $\mathrm{T}_{\mathrm{m}}$ and $\mathrm{X}_{\mathrm{c}}$ are clearly thermo-activated. The higher the exposure temperature, the shorter the induction period and the faster the decrease in $\mathrm{T}_{\mathrm{m}}$ and $\mathrm{X}_{\mathrm{c}}$. However, at $70{ }^{\circ} \mathrm{C}, \mathrm{T}_{\mathrm{m}}$ and $\mathrm{X}_{\mathrm{c}}$ remain of the same order of magnitude as their initial value (no visible change) during thermal aging, even after 511 days of exposure.

Recall that $T_{m}$ is closely related to the crystal thickness $\left(l_{C}\right)$ by the Gibbs-Thomson's relationship [46]:

$\mathrm{I}_{\mathrm{c}}=\frac{\rho_{\mathrm{c}} \Delta \mathrm{H}_{\mathrm{m} 0}}{2 \sigma_{\mathrm{e}}\left(\mathrm{T}_{\mathrm{m} 0}-\mathrm{T}_{\mathrm{m}}\right)}$

where $T_{m 0}$ is the equilibrium melting temperature, $\sigma_{\mathrm{e}}$ is the crystal surface energy, and $\rho_{\mathrm{C}}$ and $\Delta \mathrm{H}_{\mathrm{m} 0}$ are the density and melting enthalpy of the crystalline phase, respectively. The values of these different quantities are available in the literature for PVAl: $\mathrm{T}_{\mathrm{m} 0}=538 \mathrm{~K}[13], \sigma_{\mathrm{e}}=37 \times 10^{-7} \mathrm{~J} \cdot \mathrm{m}^{-2}$ [13], $\rho_{\mathrm{C}}=1350 \mathrm{~kg} \cdot \mathrm{m}^{-3}$ $[13,47]$, and $\Delta \mathrm{H}_{\mathrm{m} 0}=161 \mathrm{J.g}^{-1}[12,13]$.

Moreover, $\mathrm{X}_{\mathrm{c}}$ corresponds to weight fraction of macromolecules involved into the crystalline phase. Thus, these results would suggest a progressive disappearance of the crystalline phase.

\subsubsection{Interpretation of the structural modifications upon aging}

In order to build a realistic degradation scenario for HT-PVAl yarns at the morphological scale, let us consider the peculiar microstructure of a drawn semi-crystalline fiber suggested by Peterlin [48] and Prevorsek [49] and schematized in Fig. 20.

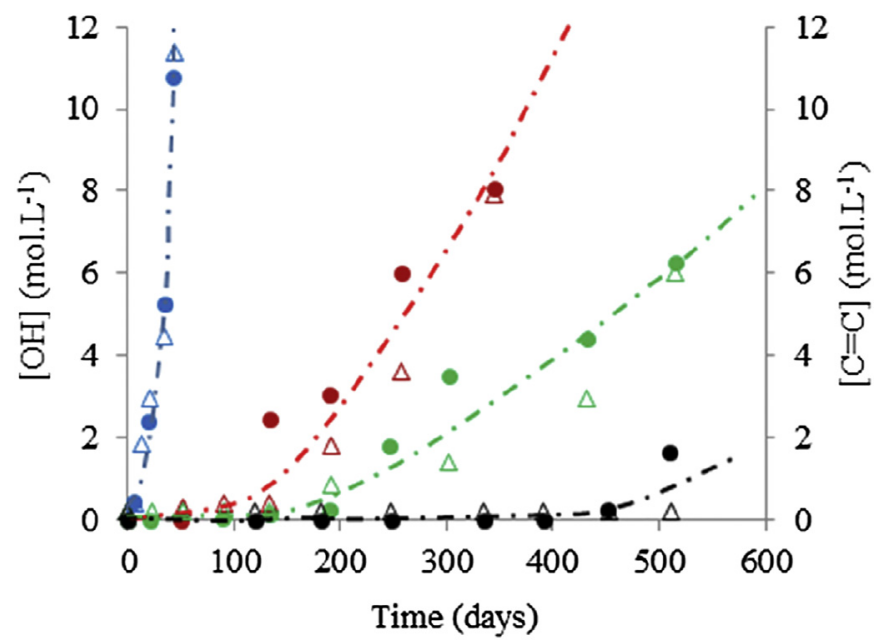

Fig. 12. Changes in the concentration of $\mathrm{OH}$ functions lost $(\bullet)$ and the total concentration of carbon-carbon double bonds formed $(\Delta)$ during the thermal aging of PVAl yarns in air at $70{ }^{\circ} \mathrm{C}$ (in black), $90{ }^{\circ} \mathrm{C}$ (green), $100{ }^{\circ} \mathrm{C}$ (red) and $120{ }^{\circ} \mathrm{C}$ (blue). (For interpretation of the references to colour in this figure legend, the reader is referred to the Web version of this article.)

This microstructure consists in parallel micro-fibrils orientated in the fiber direction and separated from each other by a thin layer of highly orientated amorphous phase, often called "mesophase" in the literature. This inter-fibrillar amorphous phase is much more rigid and presents a very reduced macromolecular chain mobility compared to the regular amorphous phase. In addition, each micro-

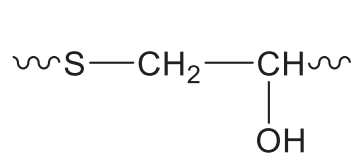
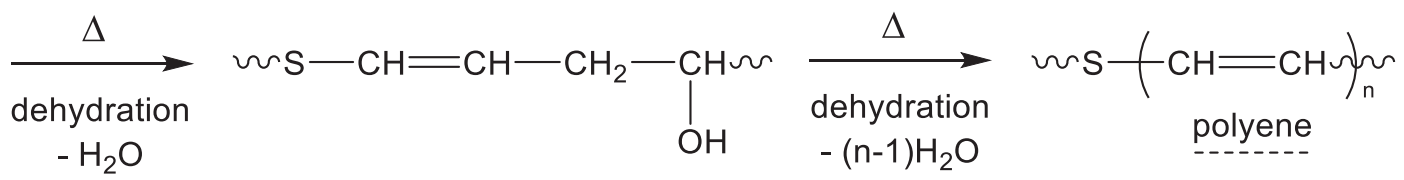

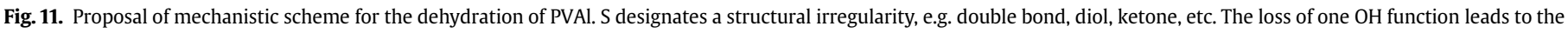
formation one double bond. 
$\sim \mathrm{CH}=\mathrm{CH}-\mathrm{CH}_{2}-\left.\right|_{\mathrm{OH}} ^{\mathrm{CH}} \sim$

+ Impurities
or radicals

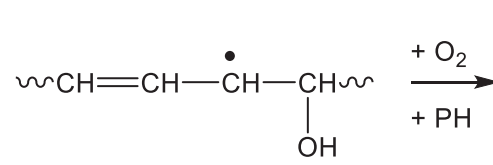<smiles>CC=CC(O)C(O)O</smiles>

$\Delta \downarrow \begin{gathered}\text { Several } \\ \text { steps }\end{gathered}$

Various types of oxidized products, for instance<smiles>CC=CC(=O)CC=CC(O)C(O)CCCCCCCCCCCCCC(=O)C(=O)O</smiles>

Fig. 13. Mechanistic scheme summarizing the thermal oxidation of allylic methylenes.

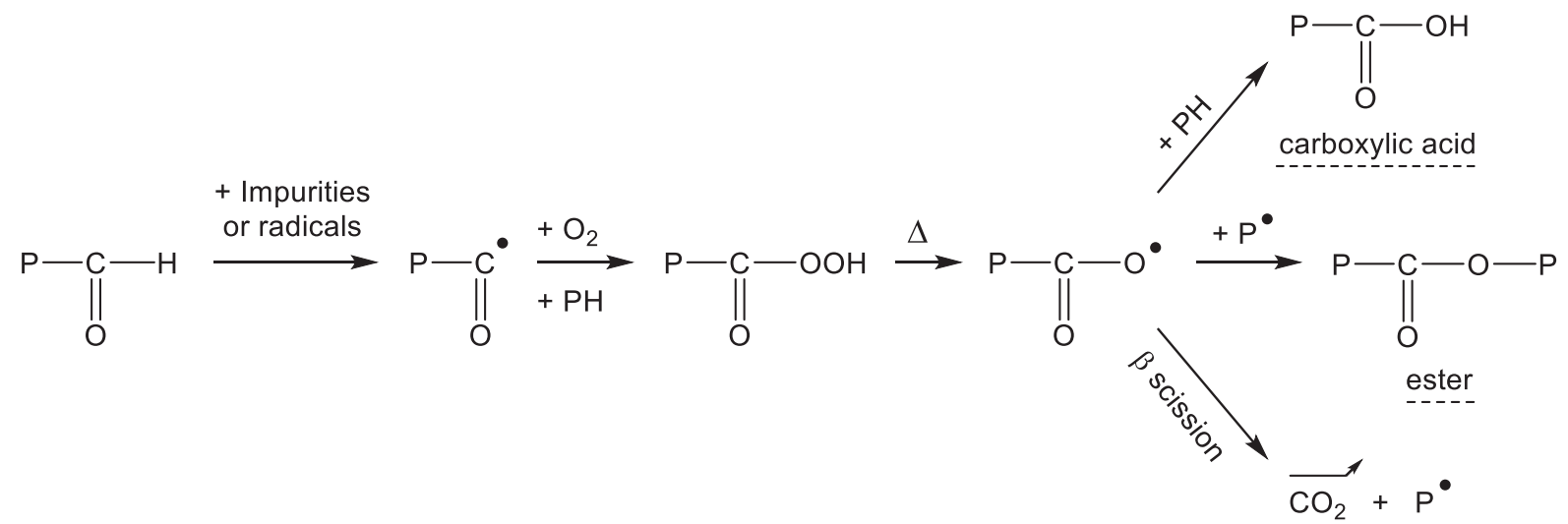

Fig. 14. Mechanistic scheme summarizing the thermal oxidation of aldehydes.<smiles></smiles>

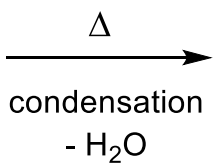<smiles>CCC1C=CC(=O)O1</smiles>

- $\mathrm{H}_{2} \mathrm{O}$

Fig. 15. Proposal of intramolecular condensation for the formation of unsaturated $\gamma$ lactones.
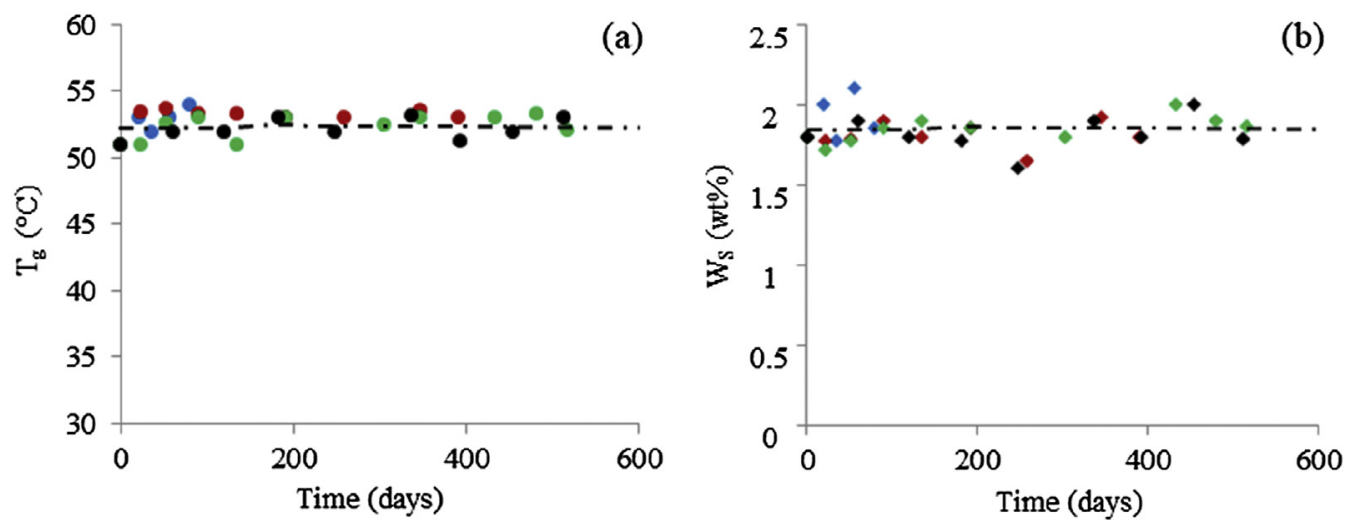

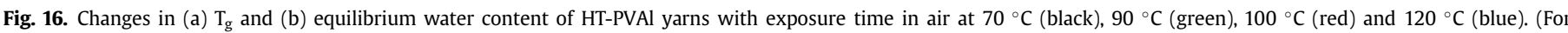
interpretation of the references to colour in this figure legend, the reader is referred to the Web version of this article.) 


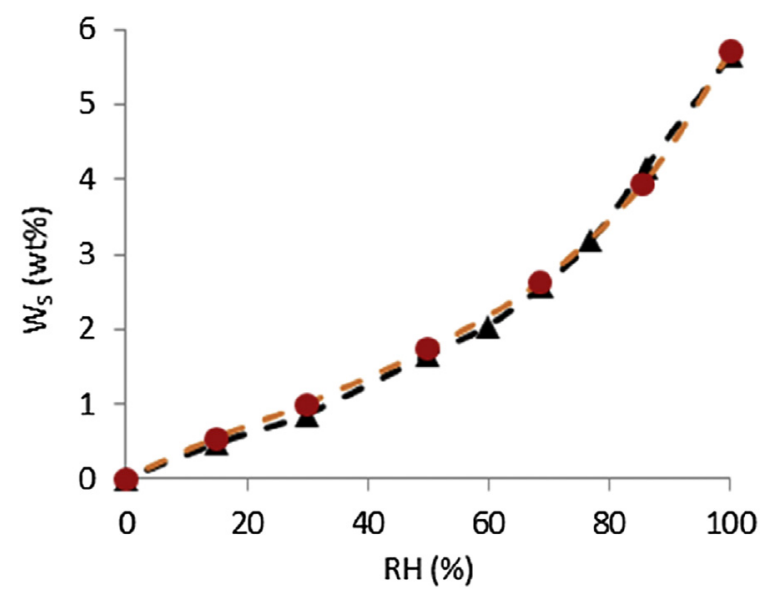

Fig. 17. Sorption isotherms at $60{ }^{\circ} \mathrm{C}$ of HT-PVAl yarns before (black) and after 345 days of thermal exposure in air at $100{ }^{\circ} \mathrm{C}$ (red). (For interpretation of the references to colour in this figure legend, the reader is referred to the Web version of this article.)

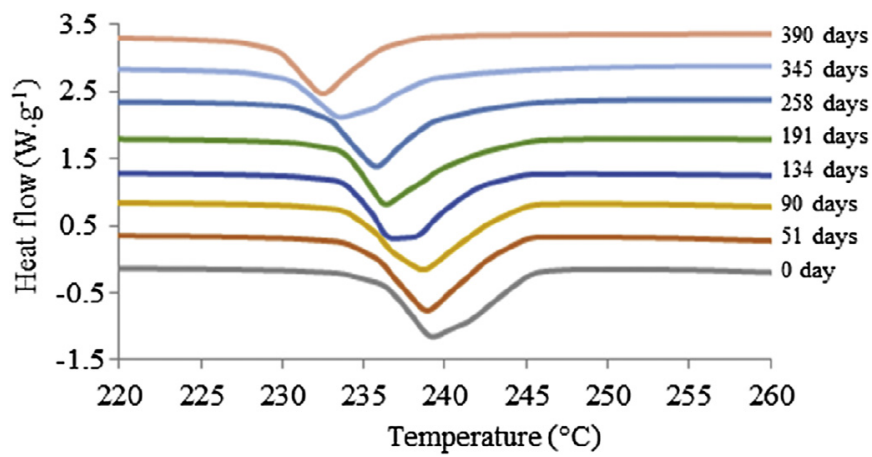

Fig. 18. Changes in the melting peak of HT-PVAl yarns during their thermal exposure in air at $100{ }^{\circ} \mathrm{C}$.

fibril is composed of a series of crystalline lamellae separated from each other by a thicker layer of amorphous phase, which is assumed to be less oriented than the inter-fibrillar amorphous phase. However, this interlamellar amorphous phase is disturbed from a thermodynamic point of view and also supports stress concentrations generated by the forced orientation of the macromolecules during the processing operation (high speed drawing of molten polymer) and exacerbated during the cooling at room temperature.

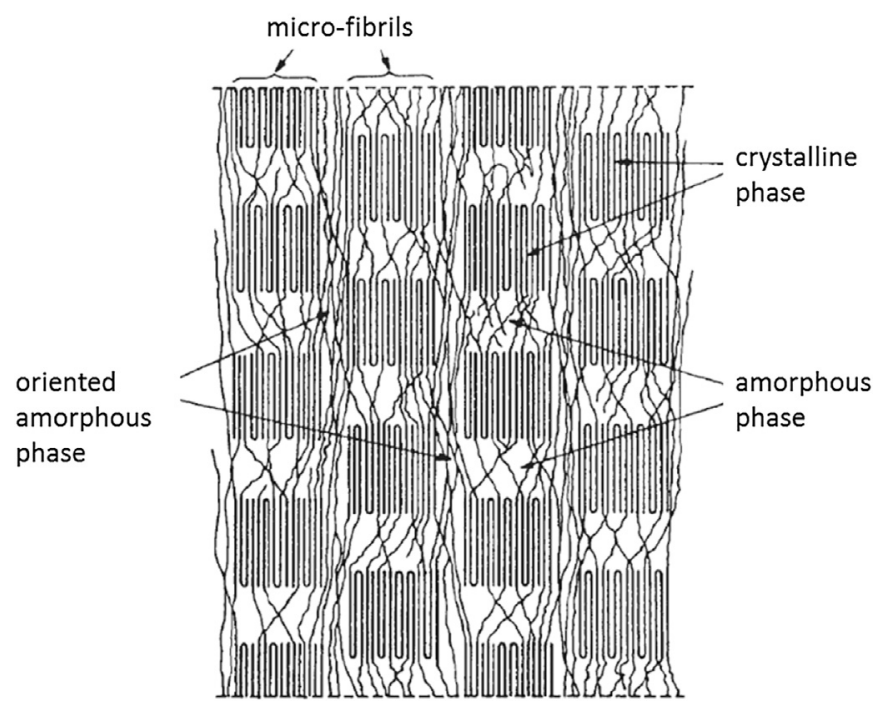

Fig. 20. Microstructural model for a drawn semi-crystalline fiber suggested by Peterlin [48] and Prevorsek [49]. The fiber axis is vertical.

No doubt, the stronger stresses are localized at the amorphous/ crystal interface.

Based on this analysis, it can reasonably be assumed that the rate of the thermal degradation is much higher at the amorphous/ crystal interphase (in particular on chain foldings), which would allow explaining the "nibbling" of the crystalline phase and its progressive transformation into amorphous phase. In addition, this scenario would allow explaining the apparent "stability" of the amorphous phase (no changes in the values of $T_{g}$ and $W_{S}$ ) in HTPVAl yarns, put in evidence in Section 3.2.1.

As each micro-fibril consists in a stacking of crystalline lamellae separated with amorphous phases [13, 49, 50], it can thus be written:

$\mathrm{I}_{\mathrm{C}}+\mathrm{I}_{\mathrm{a}}=\mathrm{I}_{\mathrm{P}}$

where $l_{c}, l_{a}$ and $l_{p}$ designate the thickness of crystalline lamellae, the interlamellar thickness (of the amorphous phase) and the long period, respectively.

According to the previous degradation scenario for which the crystalline phase is progressively transformed into amorphous phase, it can be written:
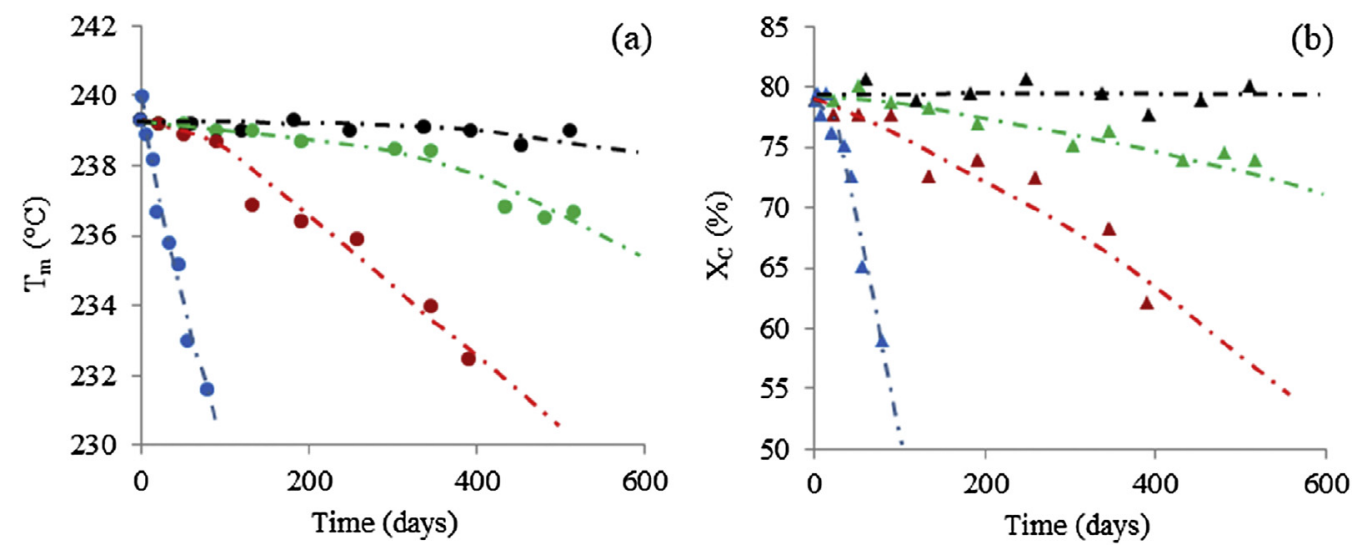

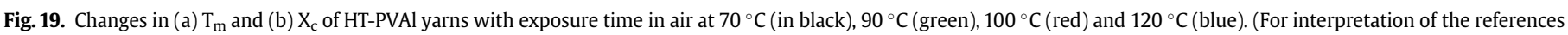
to colour in this figure legend, the reader is referred to the Web version of this article.) 
$\mathrm{I}_{\mathrm{c}}+\mathrm{I}_{\mathrm{a}}=\mathrm{I}_{\mathrm{p} 0}=$ Constant

where $l_{\mathrm{p} 0}$ designates the long period of the unaged sample. For the HT-PVAl yarns under study, $\mathrm{l}_{\mathrm{p} 0}=9.17 \mathrm{~nm}$. [50]:

In addition, the crystallinity ratio $\mathrm{XC}$ can be written as follows

$\frac{\mathrm{I}_{\mathrm{c}}}{\mathrm{I}_{\mathrm{P}}}=\frac{\mathrm{X}_{\mathrm{c}} \rho_{\mathrm{a}}}{\rho_{\mathrm{C}}-\mathrm{X}_{\mathrm{C}}\left(\rho_{\mathrm{C}}-\rho_{\mathrm{a}}\right)}$

where $\rho_{\mathrm{a}}=1.26 \mathrm{~g} . \mathrm{cm}^{-3}$ and $\rho_{\mathrm{c}}=1.35$ g.cm ${ }^{-3}[13,47]$ are the respective densities of the amorphous and crystalline phases of PVAl.

If combining Eqs. (8) and (9), it comes:

$\mathrm{I}_{\mathrm{C}}=\frac{\mathrm{I}_{\mathrm{p} 0} \mathrm{X}_{\mathrm{C}} \rho_{\mathrm{a}}}{\rho_{\mathrm{C}}-\mathrm{X}_{\mathrm{C}}\left(\rho_{\mathrm{C}}-\rho_{\mathrm{a}}\right)}$

Thus, it appears that the previous values of $X_{C}$ and $\mathrm{Tm}$ can be used to monitor the changes in the crystalline morphology of HTPVAl yarns during their thermal aging. Indeed, Eq. (10) gives immediate access to the changes in $l_{C}$, which are then introduced into Eqs. (6) and (8) to deduce the changes in the crystal surface energy $\left(\sigma_{\mathrm{e}}\right)$ and interlamellar thickness $\left(l_{\mathrm{a}}\right)$, respectively.

Fig. 21 shows the resulting changes in $l_{C}$ and $\sigma e$ for HT-PVAl yarns during the thermal exposure in air between 70 and $120^{\circ} \mathrm{C}$. As expected, the changes in $l_{C}$ are the same than those already observed for $\mathrm{T}_{\mathrm{m}}$. In addition, it is found that $\sigma e$ remains of the same order of magnitude as its initial value (no visible change) during thermal aging. This result is entirely in agreement with the proposed initial scenario of crystalline phase "nibbling". Indeed, after each nibbling event of the crystal surface, a new virgin crystal surface is formed. Therefore, no change in $\sigma_{\mathrm{e}}$ is expected. It can thus be concluded that all the experimental results obtained in this study check the validity of the proposed scenario.

\subsubsection{Mechanical properties}

The impact of thermal aging on the mechanical properties of HTPVAl yarns was studied by uniaxial tensile tests. Fig. 22 shows the changes in the strength $\left(F_{R}\right)$ and strain at rupture $\left(A_{R}\right)$ of HT-PVAl yarns during their thermal exposure in air between 70 and $120^{\circ} \mathrm{C}$. As for the crystalline parameters $\mathrm{T}_{\mathrm{m}}$ and $\mathrm{X}_{\mathrm{C}}$, above $90{ }^{\circ} \mathrm{C}, \mathrm{F}_{\mathrm{R}}$ and $A_{R}$ decrease progressively with the exposure time after an induction period. The induction period and the decay rate of $F_{R}$ and $A_{R}$ are clearly thermo-activated. The higher the aging temperature, the shorter the induction period and the faster the decrease in $F_{R}$ and $A_{R}$. In addition, at $70{ }^{\circ} \mathrm{C}, \mathrm{F}_{\mathrm{R}}$ and $\mathrm{A}_{\mathrm{R}}$ remain of the same order of magnitude as their initial value (no visible change) during thermal aging, even after 511 days of exposure.

Fig. 23 highlights the good correlation existing between the decrease in the crystalline parameters and the decrease in the fracture properties of HT-PVAl yarns. The fact that, for a given couple: crystalline parameter/fracture property, all the experimental data are placed around a single master straight-line irrespectively of the thermal exposure conditions, clearly demonstrates the validity of these structure/property relationships. As an example, the expressions of $F_{R}$ as a function of $T_{m}$ and $X_{C}$ are:

$\mathrm{F}_{\mathrm{R}}=13.15 \mathrm{~T}_{\mathrm{m}}-2984.7$

$A_{R}=5.46 \quad X_{C}-273.6$

\section{Conclusion}

This paper addressed the consequences of the thermal aging of HT-PVAl yarns in air between 70 and $120^{\circ} \mathrm{C}$ at different structural scales of analysis.

At the molecular scale, FTIR and UV-Vis spectrometries combined with chemical derivatization by ammonia gas treatment allows determining and titrating the main degradation products formed in the aged samples: isolated (at $1656 \mathrm{~cm}^{-1}$ ) and conjugated carboncarbon double bonds $\left(1592 \mathrm{~cm}^{-1}\right)$, polyenones $\left(1630 \mathrm{~cm}^{-1}\right)$, aldehydes $\left(1737 \mathrm{~cm}^{-1}\right)$, ketones $\left(1707 \mathrm{~cm}^{-1}\right)$, carboxylic acids $\left(1720 \mathrm{~cm}^{-1}\right)$ and esters $\left(1757 \mathrm{~cm}^{-1}\right)$. A detailed mechanistic scheme was proposed for the thermal aging of PVAl. In this scheme are coupled the oxidation and dehydration reactions of PVAl chains. Oxidation is a radical chain reaction preferentially occurring on the tertiary carbon carrying the alcohol function, whereas dehydration is a sequential (or "zip") water elimination initiated by the presence of structural irregularities (double bond, diol, ketone, etc.) in the PVAl chain.

At the macromolecular scale, no change in the glass transition temperature and the equilibrium water content was detected in HT-PVAl yarns by MDSC and DVS, respectively. Consequently, a heterogeneous degradation scenario preferentially located at the amorphous/crystal interface was envisaged to explain the apparent "stability" of the amorphous phase during thermal aging.

This scenario was confirmed at the morphological scale by monitoring the changes in the melting temperature and crystallinity ratio of HT-PVAl yarns by MDSC. The decreases of both crystalline parameters with exposure time indicate that the crystalline phase is
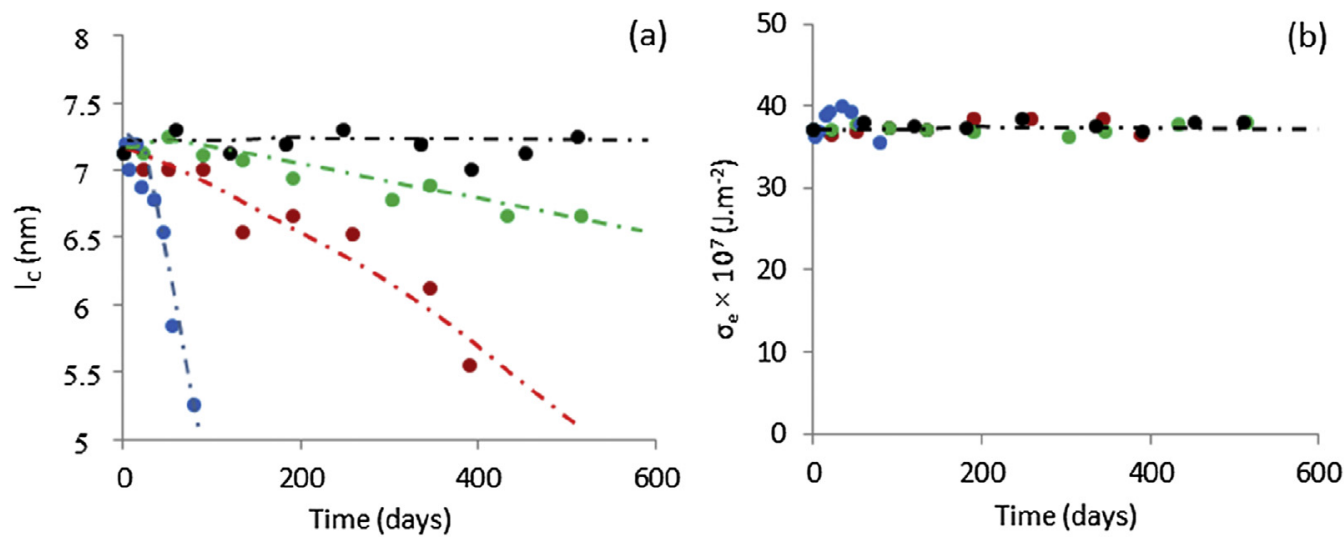

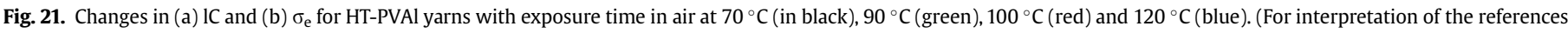
to colour in this figure legend, the reader is referred to the Web version of this article.) 

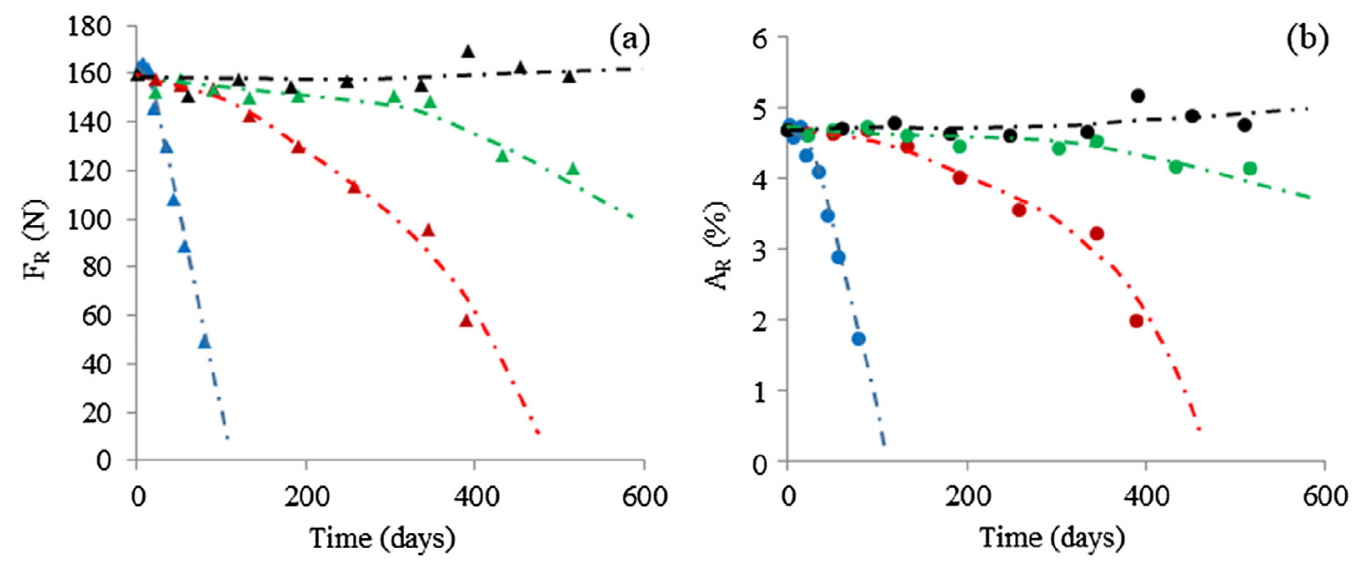

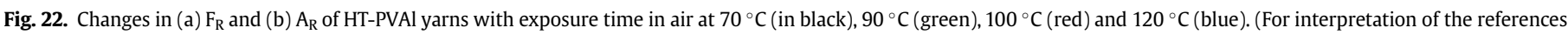
to colour in this figure legend, the reader is referred to the Web version of this article.)
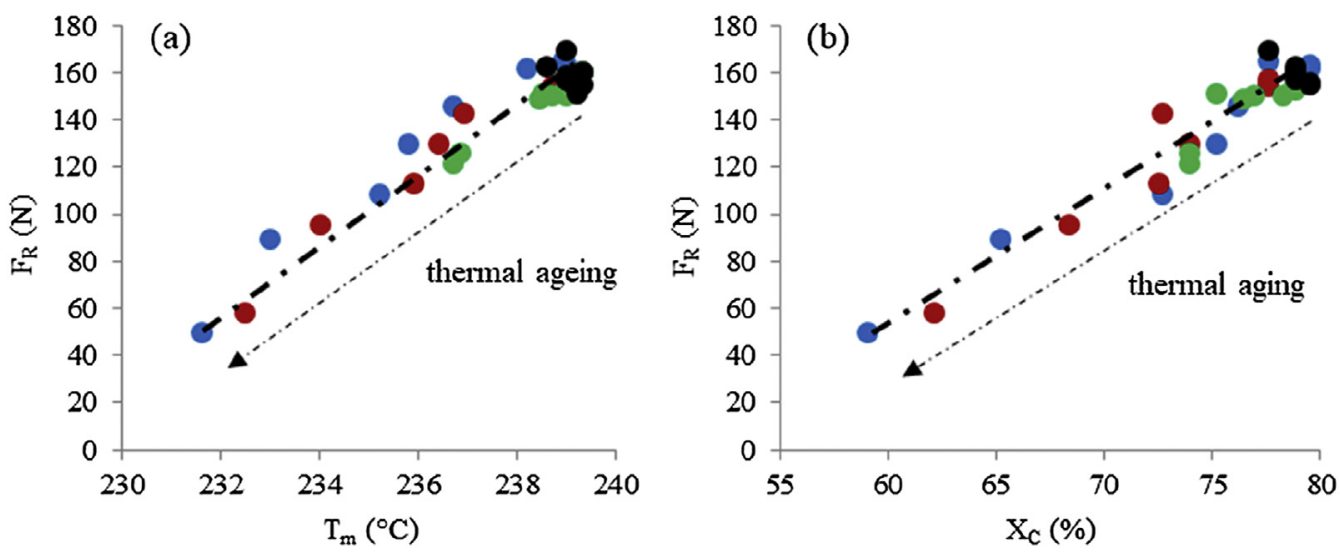

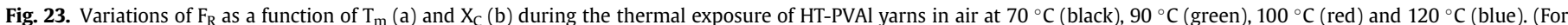
interpretation of the references to colour in this figure legend, the reader is referred to the Web version of this article.)

chemically attacked and progressively transformed into amorphous phase during thermal aging. This heterogeneous degradation induces a thinning of crystalline lamellae, whereas the crystal surface energy remains of the same order of magnitude as its initial value (no visible change) during thermal aging.

Finally, this heterogeneous degradation is responsible for the alteration of the fracture properties of HT-PVAl yarns. Linear correlations were established between crystalline parameters (related to the crystal thickness) and fracture properties (strength and strain at rupture). These structure/property relationships can now be used in industry to assess the lifetime of the products manufactured with HT-PVAl yarns (in particular, geotextiles, geogrids, geobands, etc.) and used for civil engineering applications.

\section{CRediT authorship contribution statement}

Yan Bian: Methodology, Investigation, Conceptualization, Writing - original draft. Xavier Colin: Validation, Writing - review \& editing, Supervision. Matthieu Aressy: Writing - review \& editing, Project administration, Funding acquisition.

\section{Declaration of competing interest}

The authors declare that they have no known competing financial interests or personal relationships that could have appeared to influence the work reported in this paper.

\section{References}

[1] T. Saito, T. Horikoshi, H. Hoshiro, Progress of PVA Fiber Reinforced Cementitious Composites, in: Proceedings of the 4th International Workshop on High Performance Fiber Reinforced Cementitious Composites (HPFRCC4), Ann Arbor, USA, June 2003, pp. 391-398.

[2] R. Kalbskopf, B. Lhoneux, Durability of fiber-cement roofing products, Inorg.Bond Wood Fiber Compos. Mater. 8 (2002) 347-353.

[3] K.L. Nait-Ali, N. Freitag, Renforcements à base de fibres de polyalcool de vinyle: Effect des cycles humidification/séchage et conséquences sur le dimensionnement dans le cadre des normes francaises, in: Proceedings of the Rencontres Geosynthétiques, Nantes, France, April 2009, pp. 181-188.

[4] K.L. Nait-Ali, R. Thomas, N. Freitag, Polyvinyl alcohol physical behaviour and chemical durability, in: Proceedings of the 10th International Conference on Geosynthetics (10IGC), Berlin, Germany, September 2014, pp. 385-392.

[5] I. Sakurada, Polyvinyl alcohol fibers, in: International Fiber Science and Technology Series 6, Marcel Dekker, New York, 1985.

[6] I. Sakurada, H. Matsuzawa, Oxidation of polyvinylalcohol by hydrogen peroxide, Kobunshi Kagaku 16 (1959) 565-570, 173.

[7] LCPC, Traitement des sols à la chaux et/ou aux liants hydrauliques - Application à la réalisation des remblais et des couches de forme, Guide technique, Paris, 2000.

[8] T. Le Borgne, Caractérisation et quantification des éléments perturbateurs de prise lors du traitement des sols, PhD. thesis, École National supérieure de Géologie de Nancy, France, 2010.

[9] C. Wilhelm, J.-L. Gardette, Infrared identification of carboxylic acids formed in polymer photo-oxidation, J. Appl. Polym. Sci. 51 (8) (1994) 1411-1420.

[10] I. Mkacher, Vieillissement thermique de gaines PE et PVC de câbles électriques, PhD. thesis, Arts et Métiers ParisTech, France, 2012.

[11] J.F. Pilichowski, J. Lacoste, J. Mallégol, E. Michel, F. Delor, Modification de polymères par traitements gazeux. I. Polymères alcools, polymères acides, Eur. Polym. J. 33 (10-12) (1997) 1591-1599.

[12] J.E. Mark, Polymer Data Handbook, Oxford University Press, New York, 1999.

[13] D.W. Van Krevelen, K. Te Nijenhuis, Properties of Polymers: Their Correlation 
with Chemical Structure; Their Numerical Estimation and Prediction from Additive Group Contributions, 4th ed., Elsevier, Amsterdam, 2009.

[14] K. Maruyama, H. Akahoshi, M. Kobayashi, Y. Tanizaki, Assignment of conjugate double band systems produced in heated PVA film by absorption and excitation spectra, Bull. Chem. Soc. Japan 58 (10) (1985) 2923-2928.

[15] L.V. Smirnov, N.V. Platonova, N.P. Kulikova, Electronic absorption spectra of polyvinyl alcohol, J. Appl. Spectrosc. 8 (2) (1968) 197-202.

[16] J. Gaume, P. Wong-Wah-Chung, A. Rivaton, S. Thérias, J.-L. Gardette, Photochemical behavior of PVA as an oxygen-barrier polymer for solar cell encapsulation, RSC Adv. 1 (8) (2011) 1471-1481.

[17] W.F. Forbs, R. Shilton, A. Balasubramanian, Ultraviolet absorption spectra of some conjugated dienes, J. Org. Chem. 29 (12) (1964) 3527-3531.

[18] F. Sondheimer, D.A. Ben-Efrain, R. Wolovsky, Unsaturated macrocyclic compounds. XVII. The prototropic rearrangement of linear 1,5-enynes to conjugated polyenes. The synthesis of a series of vinylogs of butadiene, J. Am. Chem. Soc. 83 (7) (1961) 1675-1681.

[19] E.A. Braude, Studies in light absorption. Part IX. The relation between absorption intensities and molecular dimensions, and its application to the electronic spectra of polyenes and polycyclic benzenoid hydrocarbons, J. Chem. Soc. (1950) 379-384 (0).

[20] P. Nayler, M.C. Whiting, Researches on polyenes. Part III. The synthesis and light absorption of dimethylpolyenes, J. Chem. Soc. (1955) 3037-3047 (0).

[21] Y. Mori, T. Honda, R. Lu, N. Hayakawa, T. Miyakoshi, Ultraviolet degradation of poly(vinyl alcohol) used in restoration of historical and cultural properties, Polym. Degrad. Stab. 114 (2015) 30-36.

[22] J. Lacoste, D.J. Carlsson, Gamma-, photo-, and thermally-initiated oxidation of linear low density polyethylene: A quantitative comparison of oxidation products, J. Polym. Sci. Polym. Chem. Ed. 30 (1992) 493-500.

[23] W.D. Domke, H. Steinke, Oxidative structures in polyolefins: FTIR method of quantitative determination, J. Polym. Sci. Polym. Chem. Ed. 24 (1986) $2701-2705$

[24] H. Aoki, A. Yoshida, T. Suzuki, The kinetic evaluation for photo-oxidation of polyvinyl alcohol, J. Soc. Mater. Sci. Japan 22 (239) (1973) 776-784.

[25] V.K. Ahluwalia, S. Dhingra, Comprehensive Practical Organic Chemistry: Qualitative Analysis, Universities Press, Hyderabad (India), 2004.

[26] M. Guyader Coquillat, Vieillissement des propergols a matrice polydutadiène modélisation cinétique de l'oxydation, PhD. thesis, Arts et Métiers ParisTech, France, 2007.

[27] M. Tabankia, J. Philippart, J.-L. Gardette, Photo-oxidation of block copoly(ether-ester) thermoplastic elastomers, Polym. Degrad. Stab. 12 (4) (1985) 349-362.

[28] D.J. Carlsson, D.M. Wiles, The photodegradation of polypropylene films. II. Photolysis of ketonic oxidation products, Macromolecules 2 (6) (1969) 587-597.

[29] J. Lacoste, D. Vaillant, D. Carlsson, Gamma-, photo-, and thermally initiated oxidation of isotactic polypropylene, J. Polym. Sci. Part A Polym. Chem. 31 (3) (1993) 715-722.

[30] P.S. Thomas, FTIR study of the thermal degradation of poly(vinyl alcohol), J. Therm. Anal. Calorim. 64 (2) (2001) 501-508.

[31] J. Tireau, Propriétés à long terme des gaines de polyéthylène haute densité utilisées pour les ponts à haubans, PhD. thesis, Arts et Métiers ParisTech, France, 2011.

[32] B.J. Holland, J.N. Hay, The thermal degradation of poly(vinyl alcohol), Polymer 42 (16) (2001) 6775-6783.

[33] H.L. McMurry, V. Thornton, Correlation of infrared spectra, Anal. Chem. 24 (2)
(1952) 318-334.

[34] J.-L. Gardette, S. Gaumet, J. Lemaire, Photooxidation of poly(vinyl chloride). I. A reexamination of the mechanism, Macromolecules 22 (6) (1989) $2576-2581$

[35] I. Boughattas, Etude de la dégradation thermique du polychlorure de vinyle : Effect couplé de l'irradiation et de la température, PhD. thesis, Université de Caen Basse-Normandie, France, 2014.

[36] J. Colombani, Etude de la radiolyse gamma du poly(chlorure de vinyle) : Application à l'étude de la dégradation par irradiation et par lixiviation du PVC industriel, PhD. thesis, Faculté des Sciences et Techniques de Marseille SaintJérome, France, 2007.

[37] M. Nishiyama, R. Yamamoto, H. Hoshiro, Long-term durability of Kuralon (PVA fiber) in alkaline condition, in: Proceedings of the 10th International Inorganic-Bonded Fiber Composites Conference, São Paulo, Brazil, November 2006.

[38] X. Colin, G. Teyssèdre, M. Fois, Ageing and degradation of multiphase polymer systems, in: A. Boudenne, L. Ibos, Y. Candau, S. Thomas (Eds.), Handbook of Multiphase Polymer Systems, Vol. 2/2, Wiley, Chichester, United Kingdom, 2011, pp. 797-841. Chap. 21.

[39] M. Da Cruz, L. Van Schoors, K. Benzarti, X. Colin, Thermo-oxidative degradation of additive free polyethylene. Part I. Analysis of chemical modifications at molecular and macromolecular scales, J. Appl. Polym. Sci. 133 (18) (2016). Paper No. 43287.

[40] S.S. Pesetskii, B. Jurkowski, Yu.M. Krivoguz, A.I. Kuzavkov, Oxidation of LDPE and LDPE grafted with itaconic acid, in contact with water, Polymer 41 (3) (2000) 1037-1043.

[41] R. Broska, J. Rychly, K. Csomorova, Carboxylic acid assisted oxidation of polypropylene studied by chemiluminescence, Polym. Degrad. Stab. 63 (2) (1999) 231-236.

[42] P. Alexy, I. Lacık, B. Šimková, D. Bakoš, N. Prónayová, T. Liptaj, S. Hanzelová, M. Várošová, Effect of melt processing on thermo-mechanical degradation of poly(vinyl alcohol)s, Polym. Degrad. Stab. 85 (2) (2004) 823-830.

43] X. Colin, J. Verdu, Humid ageing of organic matrix composites, in: P. Davies, Y.D.S. Rajapakse (Eds.), Solid Mechanics and its Applications, Vol. 208: Durability of Composites in a Marine Environment, Springer, Dordrecht, 2014 pp. 47-114. Chap. 3.

[44] G.S. Park, Transport principles - solution, diffusion and permeation in polymer membranes, in: P.M. Bungay, H.K. Lonsdale, M.N. Pinho (Eds.), Synthetic Membranes: Science, Engineering and Applications, Reidel Publishing Company, Dordrecht, 1986, pp. 57-107.

[45] M. Lacuve, X. Colin, L. Perrin, L. Flandin, P. Notingher, C. Tourcher, M. Ben Hassine, H. Tanzeght, Investigation and modelling of the water transport properties in unfilled EPDM elastomers, Polym. Degrad. Stab. 168 (2019) Paper No. 108949

[46] G. Teyssèdre, C. Lacabanne, Caractérisation des polymères par analyse thermique, in: Techniques de l'Ingénieur, AM 3274, 1997, pp. 1-8.

[47] J.G. Pritchard, in: Poly(Vinyl Alcohol) - Basic Properties and Uses, Gordon and Breach Science Publishers, West Ham, London, 1970, p. 41.

[48] A. Peterlin, Structural model of mechanical properties and failure of crystalline polymer solids with fibrous structure, Int. J. Fract. 11 (5) (1975) 761-780.

[49] D.C. Prevorsek, P.J. Harget, R.K. Sharma, A.C. Reimschuessel, Nylon 6 fibers: Changes in structure between moderate and high draw ratios, J. Macromol. Sci. Part B Phys. 8 (1-2) (1973) 127-156.

[50] J. Verdu, Vieillissement Oxydant des Polymères - Aspects Cinétiques, Hermès Science Publications, Paris, 2012. 